\title{
Original composition and formation process of slab-derived deep brine from Kashio mineral spring in central Japan
}

\author{
Fumitake Kusuhara ${ }^{* *}$, Kohei Kazahaya ${ }^{2}$, Noritoshi Morikawa ${ }^{2}$, Masaya Yasuhara ${ }^{3}$, Hidemi Tanaka ${ }^{4}$, \\ Masaaki Takahashi² and Yuki Tosaki²
}

\begin{abstract}
Brine samples from the wells in the Kashio mineral spring (an "Arima-type" hot spring at Ooshika-Mura, central Japan) were analyzed to determine the original chemical and isotopic compositions of the deep brine end-member before its dilution by meteoric water and to elucidate the origin of the end-member. The trends of variation between $\mathrm{Cl}, \delta \mathrm{D}$, and $\delta^{18} \mathrm{O}$ indicated the existence of a two-component mixing system and a systematic variation in the mixing ratio, which were mentioned in previous studies. By carefully tracking the variation in tritium $\left({ }^{3} \mathrm{H}\right)$ and atmospheric noble gas in the brine, the $\mathrm{Cl}$ concentration in the end-member was determined to be $24,000 \mathrm{mg} / \mathrm{L}$. This value is consistent with the result of previous studies. Based on the estimated composition and other related data, we inferred that the end-member originated from slab-derived fluid, which in turn may have undergone oxygen isotope exchange reactions with minerals. Although both the Arima and Kashio brines are considered to be derived from fluid dehydrated from the Philippine Sea slab, the chemical and isotopic compositions of the Kashio end-member are different from those of the Arima end-member. In particular, the Kashio end-member is characterized by low $\mathrm{Cl}$ concentration ( 40\% lower than that in the Arima end-member), low hydrogen isotope ratio, and low ${ }^{3} \mathrm{He} /{ }^{4} \mathrm{He}$ ratio (1.4 Ra). These results indicate that the chemical and isotopic compositions of the slab-derived fluid are different for each location. The significant difference in $\delta \mathrm{D}$ could reflect the difference in the dehydration depth. Finally, the low temperature and relatively low ${ }^{3} \mathrm{He} /{ }^{4} \mathrm{He}$ ratio of the brine end-member could be explained by its long residence time within the crust.
\end{abstract}

Keywords: Kashio mineral spring, Arima-type hot spring, Slab-derived fluid, Chemical and isotopic composition, Tritium, Noble gas

\section{Introduction}

The Kashio mineral spring in Ooshika-Mura, central Japan, is well known for its unusual brine. The origin, as well as the chemical and isotopic characteristics of the brine, has been previously studied. This brine should not contain present seawater considering its distance from the coast. (Nakamura and Maeda 1958; Matsubaya et al. 1980; Matsubaya 1981; Hashizume 1984; Takamatsu et al. 1986; Masuda et al. 1988; Muramatsu et al. 2016).

\footnotetext{
*Correspondence: kusuhara@criepi.denken.or.jp

${ }^{1}$ Central Research Institute of Electric Power Industry (CRIEPI), 1646 Abiko, Abiko, Chiba 270-1194, Japan

Full list of author information is available at the end of the article
}

Nakamura and Maeda (1958) measured the concentrations of major ions, $\mathrm{Br}$, and I in a Kashio brine sample and found that $\mathrm{Cl}$ content was equal to that of seawater. Matsubaya et al. (1980) defined the trend from meteoric water toward the end-members of the Arima, Takarazuka, and Ishibotoke hot spring samples (located in the Kinki district, southwestern of Japan) (Matsubaya et al. 1973) based on $\delta \mathrm{D}-\delta^{18} \mathrm{O}$ and $\delta \mathrm{D}-\mathrm{Cl}$ diagrams. Matsubaya (1981) classified the Arima, Takarazuka, Ishibotoke, and Kashio hot springs as "Arima-type" and suggested that the dilution of the same brine end-member by meteoric water in the different locations led to the formation of the local brines. However, the supporting evidence 
was not sufficient. Notably, all "Arima-type" hot springs are located far away from Quaternary volcanoes. Masuda et al. (1988) periodically collected and analyzed Kashio brine samples for $\sim 1$ year. They suggested that the Kashio brine is a mixture of a deep brine end-member and meteoric water, and that the mixing ratio varied seasonally.

The Arima-type brine end-member is generally considered to have originated from slab-derived fluid, although this hypothesis is yet to be proven by direct evidence (Nishimura et al. 2006; Kazahaya et al. 2014). Subducted slabs contain water in the form of pore water and hydrous minerals. Water is released from slabs during consolidation and diagenesis at shallow depths and during metamorphism at greater depths (Kazahaya et al. 2014). In southwestern Japan, it is thought that water is derived from the Philippine Sea slab and wells along the large faults without the generation of magma (Amita et al. 2014; Kazahaya et al. 2014; Morikawa et al. 2016). Although some critical issues remain unresolved (e.g., hydrogen and oxygen-isotopic fractionation within the mantle and crust) (Matsubaya 2009), the slab-derived fluid hypothesis is supported by the following findings: (1) the $\delta \mathrm{D}$ and $\delta^{18} \mathrm{O}$ values of the estimated Arima-type end-member are similar to those of island arc magma water (Giggenbach 1992); (2) hot spring water with a high ${ }^{3} \mathrm{He} /{ }^{4} \mathrm{He}$ ratio was discovered in the Kinki district, southwestern Japan, suggesting the contribution of helium from the mantle (Sano and Wakita 1985; Matsumoto et al. 2003; Morikawa et al. 2008, 2016); (3) nonvolcanic deep low-frequency tremors and earthquakes likely related to thermal fluids (Obara 2002; Nugraha and Mori 2006) have occurred in southwestern Japan; (4) the calculated $\delta \mathrm{D}$ and $\delta^{18} \mathrm{O}$ values of water released from subducted slabs are consistent with those of the Arima hot spring end-member (Kusuda et al. 2014).

In Matsubaya et al. (1980) and Matsubaya (1981), the Kashio mineral spring was classified as "Arima-type" based on the $\delta \mathrm{D}, \delta^{18} \mathrm{O}$, and $\mathrm{Cl}$ trends. Many subsequent studies have been conducted based on this classification. However, it is still unclear whether the brine at the Kashio mineral spring derives from the same end-member as other Arima-type brines. Masuda et al. (1988) assumed that the most saline water sample would have corresponded to that derived from the end-member. This water was estimated to contain much less $\mathrm{Cl}$ than that in the end-member of the Arima hot spring (Masuda et al. 1985; Kusuda et al. 2014); however, Masuda et al. (1988) did not specify whether they were referring to the actual end-member (no contribution of meteoric water) or to the diluted Arima end-member (as described by Matsubaya et al. (1980) and Matsubaya (1981)).

There are various hypotheses about the origin of the Kashio brine. For example, it may have originated from a slab-derived fluid (Kazahaya et al. 2014), water related to magmatism (Nakamura and Maeda 1958), fossil sea water (Hashizume 1984; Takamatsu et al. 1986), or residual water of submarine hydrothermal deposits (Muramatsu et al. 2016). However, none of these hypotheses has been confirmed yet.

In this study, for the first time, we report periodic data of the ${ }^{3} \mathrm{H}, \mathrm{He}$, and Ne concentrations in the Kashio brine, together with ion concentrations and stable isotopic ratio. The chemical and isotopic composition of the Kashio deep brine end-member (KDE) was carefully estimated considering the variations in ${ }^{3} \mathrm{H}, \mathrm{He}$, and $\mathrm{Ne}$. We explored the potential origin of the KDE based on the estimated compositions and related data and finally compared the compositions of the KDE and of the Arima end-member. The results of this study clarify the similarities and differences between the KDE and the Arimatype end-member, and contribute to our understanding of the characteristics of slab-derived fluids.

\section{Geological setting and sampling locations}

Ooshika-Mura is located in the southern part of Nagano Prefecture, central Japan (Fig. 1a). Figure 1b shows the surface geology of the study area and the sampling sites. The major geological units are separated by Japan's longest fault zone: the Median Tectonic Line (MTL). The Ryoke belt, which primarily consists of gneissose tonalite (Shibata and Takagi 1988), and the Kashio mylonite, both lie west of the MTL. The Sanbagawa belt, which primarily consists of Triassic-Jurassic pelitic, psammitic, and quartz schists (Uesugi and Arai 1999), lies east of the MTL. The Mikabu belt, which consists of Cretaceous basaltic and ultramafic rocks, is located east of the Sanbagawa belt (Isozaki and Maruyama 1991). The Shiokawa peridotite, Iriyamazawa hornblende gabbro, and Ogawara ultrabasic rocks are all ultramafic rocks in the Mikabu belt (Iizumi 1968; Makimoto 1978; Uesugi and Arai 1999). The Chichibu belt, which is composed of Jurassic pelitic rocks, sandstone, chert, and limestone (Uesugi and Arai 1999), lies east of the Mikabu belt. Meanwhile, the Shimanto belt lies in the easternmost part of the study area and consists of Cretaceous sedimentary rocks: predominantly massive sandstones with alternating layers of sandstone and mudstone (Kawabata 1984). The MTL approximately runs NNE to SSW across this area, with its fault plane varying from vertical to dipping westerly at a steep angle in outcrops (Tanaka and Hara 1990; Tanaka et al. 1996). Seismic experiments have shown that the MTL plane extends westward at a steep angle down to a depth of $\sim 30 \mathrm{~km}$ (Ito 2016).

The Kashio mineral spring is located at the center of Ooshika-Mura. Two wells inside the Kashio mineral spring area (indicated as "A" and "B" in our study) 


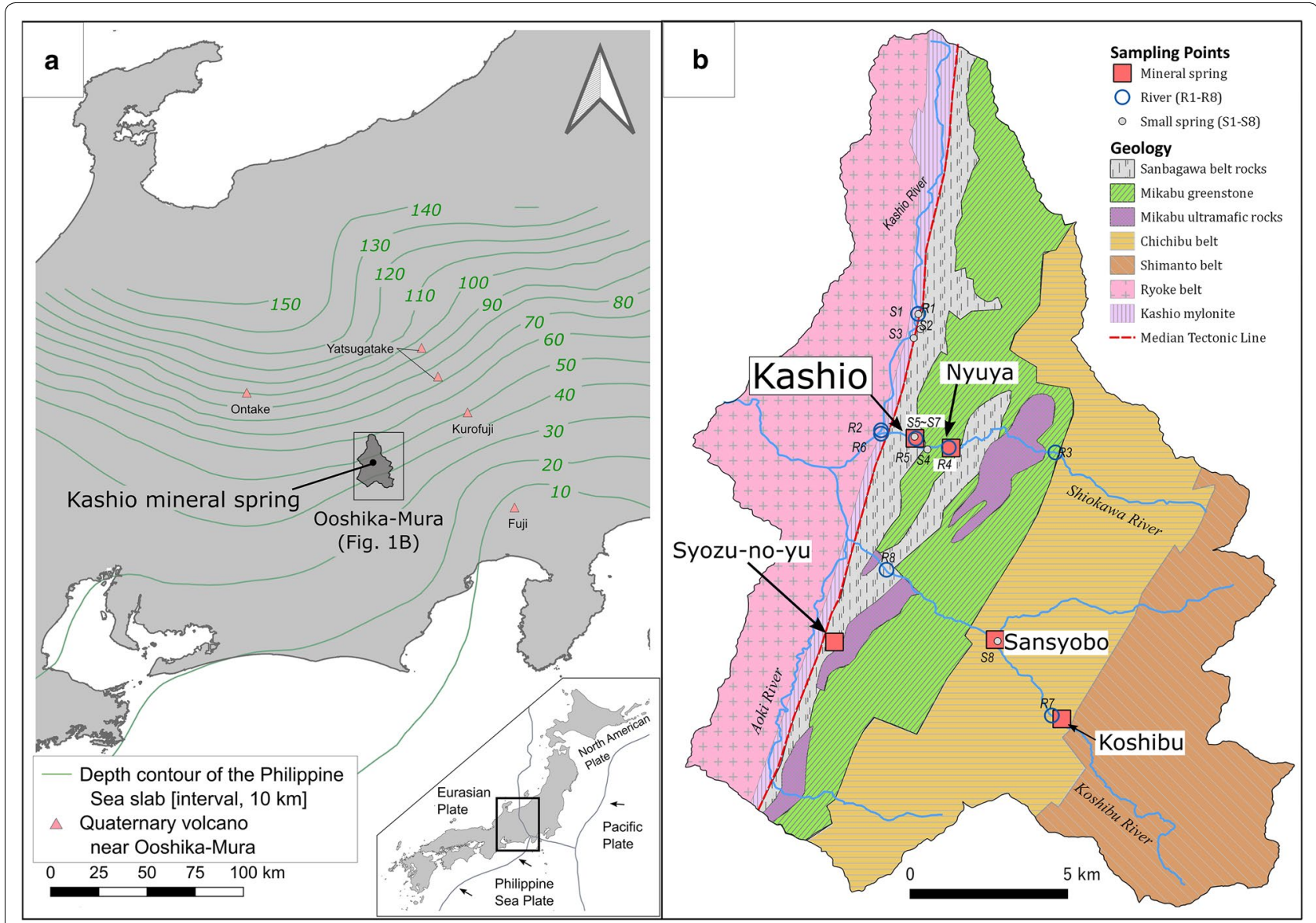

Fig. 1 Location and geological setting of the Kashio mineral spring. a Location of the Ooshika-Mura and the Kashio mineral spring. b Geological setting of Ooshika-Mura and the positions of the sampled water (red squares: mineral springs, blue open circles: river, small gray circles: small springs). Depth contours and geology were modified from GeomapNavi (2018)

are spaced $\sim 6 \mathrm{~m}$ apart and located $\sim 1 \mathrm{~km}$ east of the MTL. According to their owner, these wells both penetrate psammitic and pelitic schists of the Sanbagawa belt down to depths of $\sim 10 \mathrm{~m}$. In the surrounding area there are four other mineral springs: the Nyuya spring is $\sim 1 \mathrm{~km}$ east of Kashio (detailed well data were unavailable), whereas the Syozu-no-yu spring is located in the southern part of Ooshika-Mura and its water gushes naturally near the Mikabu ultramafic rock; moreover, the Sansyobo and Koshibu springs are located on the Chichibu belt and both discharge via drilled wells. Four rivers (i.e., Kashio, Shiokawa, Koshibu, and Aoki) run through the study region. All the mineral springs previously mentioned discharge near these rivers.

Through a preliminary exploration, we discovered that some additional small springs also discharge near these rivers. We refer to these springs as "small springs".

\section{Water samples and experimental procedures}

The Kashio A and B water samples were collected approximately once a month from May 2016 to November 2016 (Table 1) at the sites indicated in Fig. 1b. The Kashio B well was commercially used, and a few tons of brine were drawn for approximately $5 \mathrm{~h}$ from the well by a submersible pump once or twice a month. Water samples were collected from the Kashio B well several times during each commercial pumping: in June (KNK-16-M010), July (KNK-16-M012, M013, M014), and September (KNK-16-M021, M022, M023). The lapse times from the start of each commercial pumping to each water sampling are also shown in Table 1. It took $30 \mathrm{~min}$ to collect a set of water samples. Additional Kashio B samples were collected when no commercial pumping was conducted. Two samples were collected in September from the Kashio A well during the commercial pumping at the Kashio B well (KNK16-M024, M025). This was done in order to test for any 


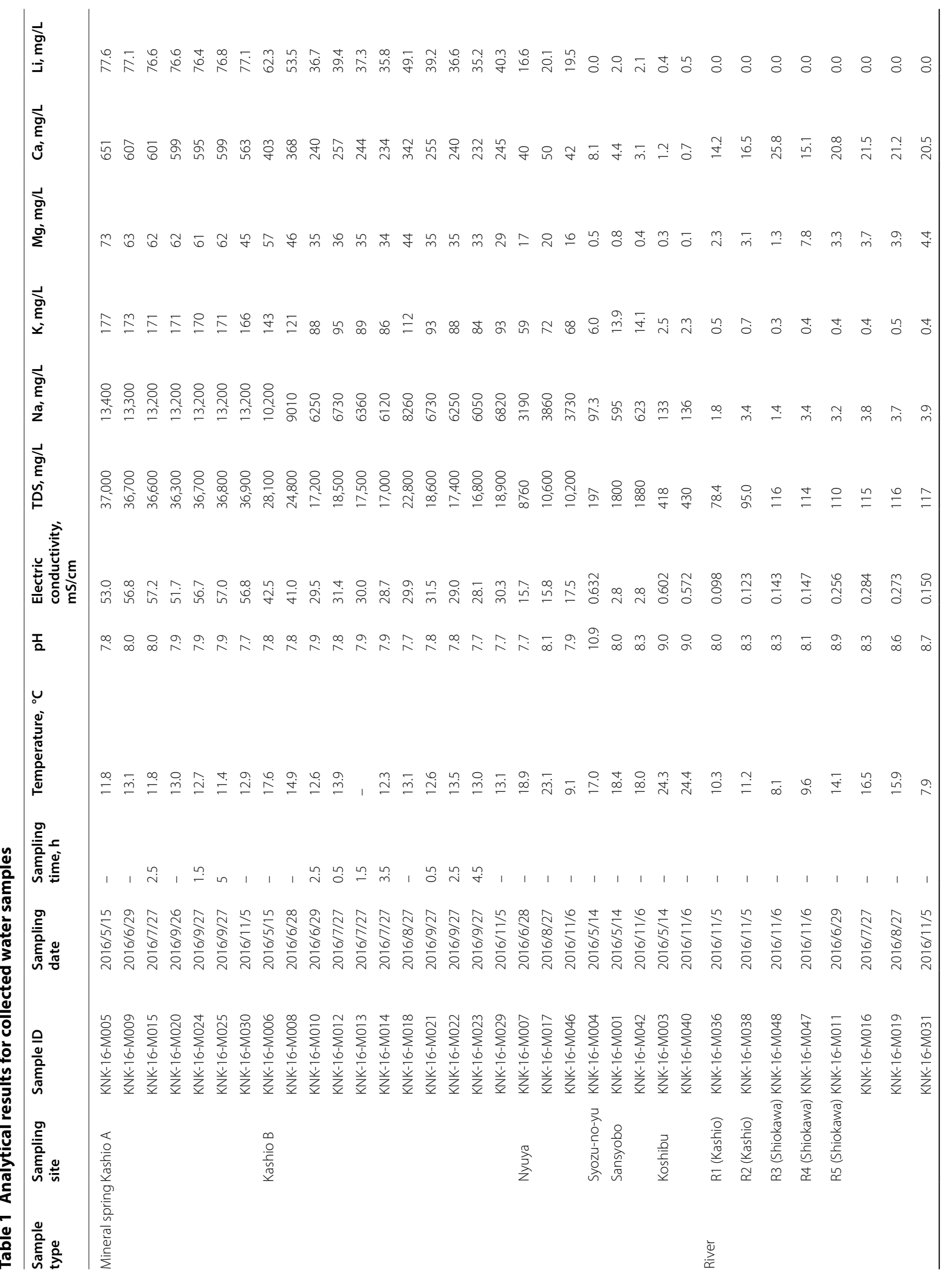




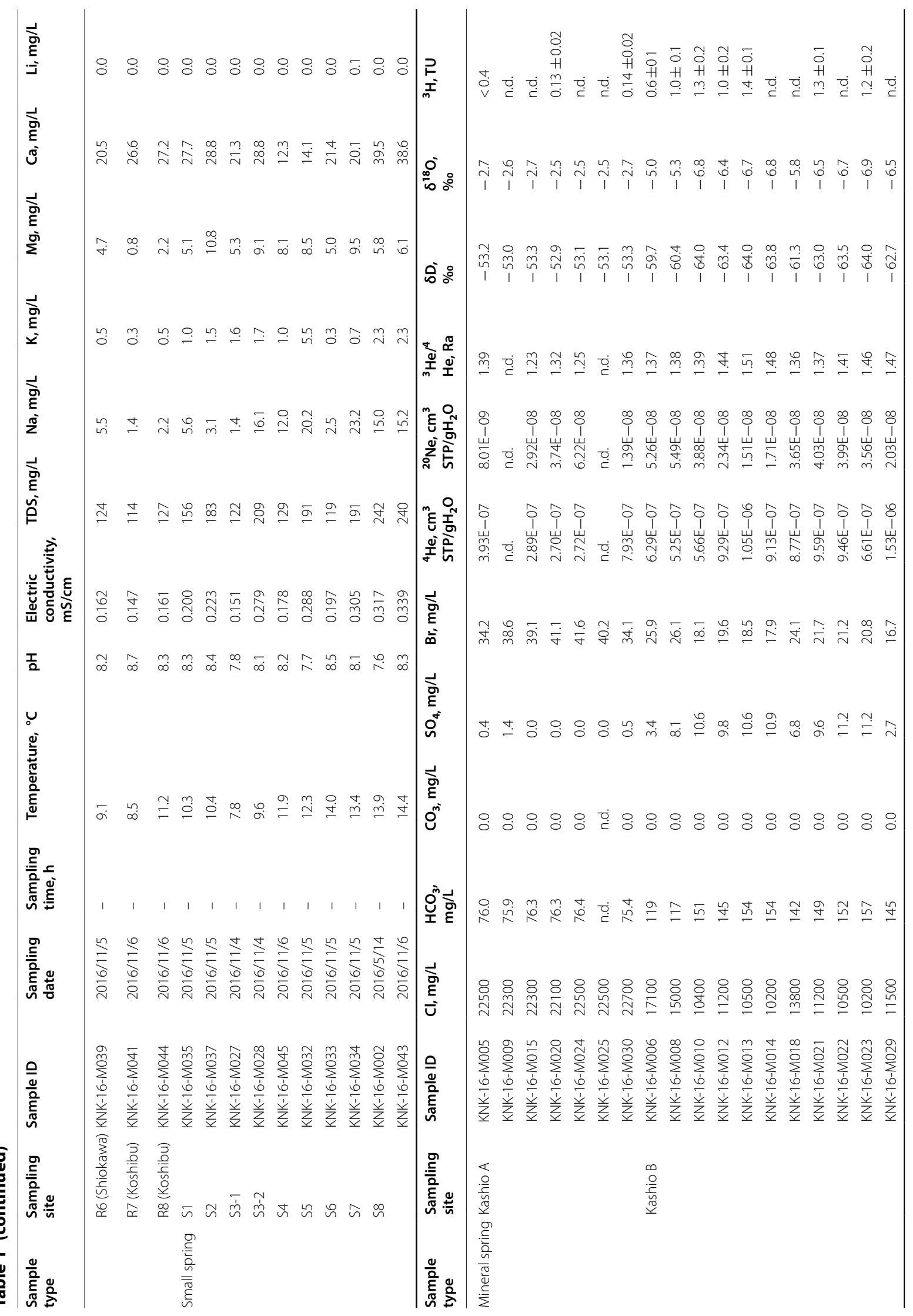




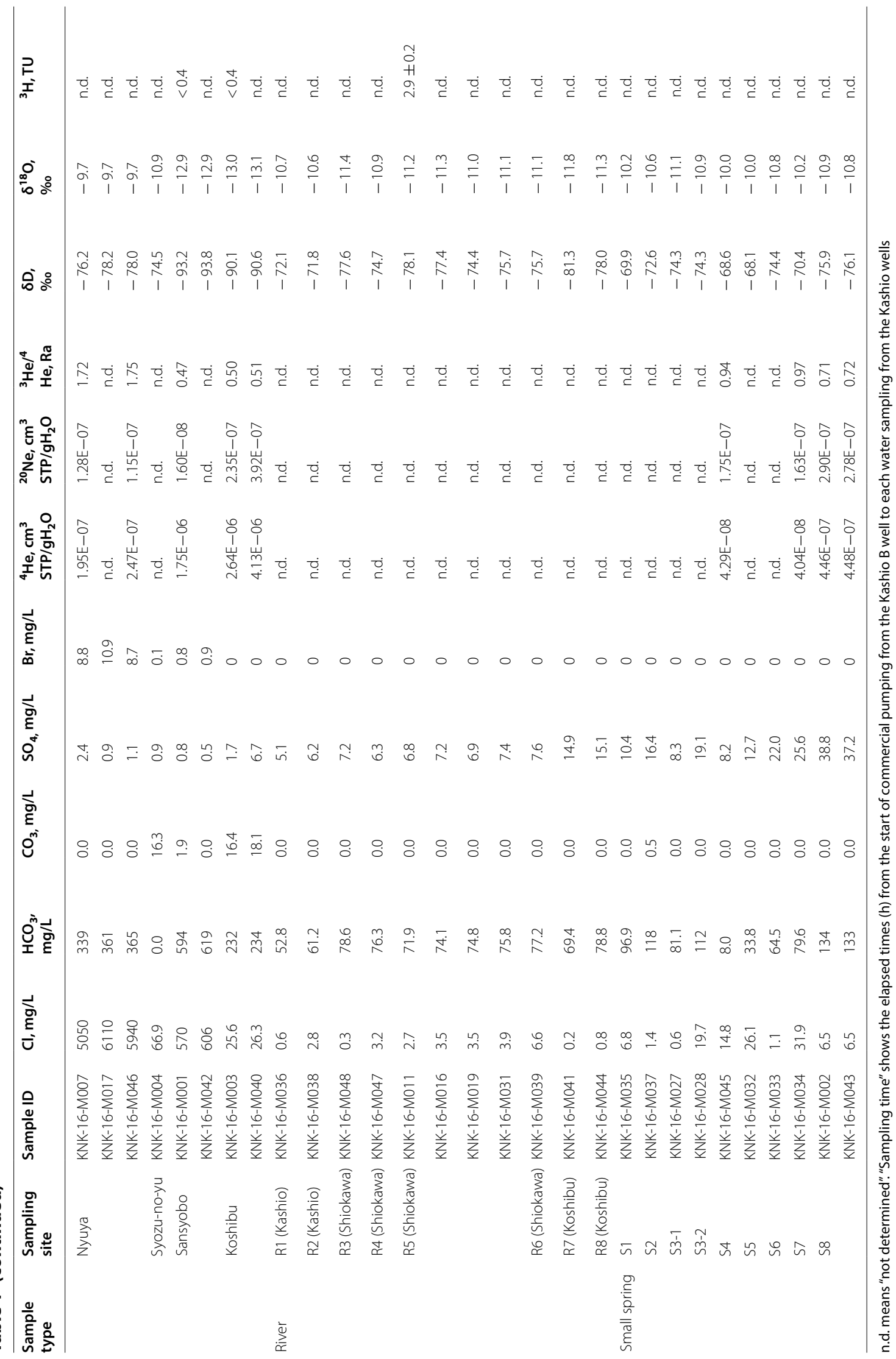


influence of the pumping at the Kashio B well on the Kashio A well. Samples were also collected from the other four mineral springs previously mentioned. For comparison, water samples were also collected from the Shiokawa, Kashio, and Koshibu Rivers and from some small springs. A total of 47 samples were collected from 23 sites (Table 1 ).

Plastic bottles were used for the collection of samples to be analyzed for water chemistry, oxygen and hydrogen isotopes, and ${ }^{3} \mathrm{H}$ concentration. The measurements were performed at the National Institute of Advanced Industrial Science and Technology, Geological Survey of Japan (GSJ), in Tsukuba, Japan. The major element, $\mathrm{Li}$, and $\mathrm{Br}$ concentrations were measured by ion chromatography (Thermo Fisher Scientific DXi500 and ICS-2100); moreover, the concentrations of $\mathrm{HCO}_{3}$ and $\mathrm{CO}_{3}$ were determined by using an automatic potentiometric titrator (Kyoto Electronics Manufacturing AT-510). Hydrogen isotope ratios were measured by cavity ring-down spectroscopy (Picarro L2120-i), whereas the oxygen isotope ratios were measured by isotope ratio mass spectrometry (Thermo Fisher Scientific DELTA plus). The measurement errors for $\delta \mathrm{D}$ and $\delta^{18} \mathrm{O}$ were lower than $\pm 1 \%$ and $\pm 0.1 \%$, respectively. The water samples for the ${ }^{3} \mathrm{H}$ analysis were distilled using a rotary evaporator (Buchi Rotavapor R-6). The ${ }^{3} \mathrm{H}$ concentrations were enhanced by electrolytic enrichment (Permelec Electrode Tripure XZ030) and measured using a liquid scintillation counter (Perkin Elmer Tri-Carb 3180TR/SL). Because the Kashio A sample (KNK-16-M005) contained less ${ }^{3} \mathrm{H}$ than the detection limit of the instruments at the GSJ (0.4 TU), two samples (i.e., KNK-16-M020 and M030) were analyzed at the Tritium and Water Dating Laboratory, GNS Science, in New Zealand (Morgenstern and Taylor 2009). These samples were electrolytically enriched prior to measurement using a Quantulus liquid scintillation counter (Perkin Elmer, Inc.), with a detection limit of $0.03 \mathrm{TU}$.

The water samples for the $\mathrm{He}$ and $\mathrm{Ne}$ analyses were collected in annealed copper tubes having a 3/8-inch $(0.95 \mathrm{~cm})$ o.d. and a length of $30 \mathrm{~cm}$. The $\mathrm{He}$ and $\mathrm{Ne}$ dissolved in the samples were extracted into glass ampules, following the procedure described by Jean-Baptiste et al. (1992), and then sealed by flame. The permeation of helium into the glass ampules during storage was negligible $\left(\sim 2 \times 10^{-9} \mathrm{~cm}^{3} \mathrm{STP} /\right.$ year $)$. The $\mathrm{He}$ and $\mathrm{Ne}$ concentrations and helium isotope ratios were measured using a static noble gas mass spectrometer (Micromass MM5400) at the GSJ. The technical details of this analysis were described by Morikawa et al. (2008). Ten repeated analyses of the ${ }^{3} \mathrm{He} /{ }^{4} \mathrm{He}$ ratios and $\mathrm{He}$ and $\mathrm{Ne}$ concentrations were conducted on the air-saturated water samples, for an average standard deviation $(1 \sigma)$ of $\pm 3 \%$.

\section{Results}

\section{Water temperature and $\mathrm{pH}$}

The results of the chemical and isotopic analyses of the collected samples, together with their physical parameters, are shown in Table 1.

The water temperature and $\mathrm{pH}$ at the Kashio A and $\mathrm{B}$ wells remained approximately constant over the measurement period. Figure 2 shows the water temperature and $\mathrm{pH}$ plotted versus the $\mathrm{Cl}$ concentrations of the correspondent samples. The $\mathrm{pH}$ was consistently $\sim 7.8$, whereas the $\mathrm{Cl}$ concentration varied (Fig. 2a). Water temperature showed a weak negative correlation with $\mathrm{Cl}$, although two anomalous values were obtained from Kashio B samples (i.e., KNK-16-M006 and -M008) (Fig. 2b).

Water temperature and $\mathrm{pH}$ were measured twice during the observation period at the Sansyobo and Koshibu mineral springs, obtaining similar values. The water from the Nyuya mineral spring showed a constant $\mathrm{pH}$, but a seasonal temperature variation (Table 1). Upwelling water from the Nyuya well was transferred to a tank on the ground, and samples were collected from it. This may partially explain the seasonal variation in temperature of the Nyuya samples.

\section{Chemical and isotopic compositions}

The Kashio A, Kashio B, Nyuya, and Syozu-no-yu waters were all of the $\mathrm{Na}-\mathrm{Cl}$ type. The $\mathrm{Cl}$ concentrations in the corresponding water samples were $\sim 23,000 \mathrm{mg} / \mathrm{L}$, $10,000-17,000 \mathrm{mg} / \mathrm{L}, 5000-6000 \mathrm{mg} / \mathrm{L}$, and $\sim 70 \mathrm{mg} / \mathrm{L}$, respectively. Meanwhile, the Sansyobo and Koshibu waters were of $\mathrm{Na}-\mathrm{Cl}-\mathrm{HCO}_{3}$ and $\mathrm{Na}-\mathrm{HCO}_{3}$ types, respectively. The total dissolved solids (TDS) in the Sansyobo water were more abundant than in the Koshibu water. Finally, river water was of the $\mathrm{Ca}-\mathrm{HCO}_{3}$ type, whereas the water from the small springs mainly contained $\mathrm{Na}, \mathrm{Ca}, \mathrm{Cl}$, and $\mathrm{HCO}_{3}$.

The TDS and the concentration of each element in the Kashio A water remained almost constant during the sampling period (Table 1). On the contrary, those in the Kashio B water varied in the same way as $\mathrm{Cl}$ and alkalinity in Masuda et al. (1988). The chemical compositions of the Kashio A samples and of KNK-16-M006 (the most saline Kashio B water sample) were approximately consistent with those reported in previous studies (Nakamura and Maeda 1958; Takamatsu et al. 1986; Muramatsu et al. 2016). Variations of the $\mathrm{Cl}(10,200-$ $17,100 \mathrm{mg} / \mathrm{L})$ and $\mathrm{HCO}_{3}(117-157 \mathrm{mg} / \mathrm{L}$ ) concentrations in the Kashio B water were within the ranges reported by 
Masuda et al. (1988). We collected water samples more than once from Nyuya, Sansyobo, and Koshibu mineral springs. The waters of these springs showed only slight variations in the TDS concentrations.

A $\delta \mathrm{D}-\delta^{18} \mathrm{O}$ diagram is shown in Fig. 3a. The $\delta \mathrm{D}$ and $\delta^{18} \mathrm{O}$ values obtained for the Kashio $\mathrm{A}$ and $\mathrm{B}$ samples varied during the sampling period, following a linear trend distinct from the global meteoric water line (Craig 1961) and including higher $\delta \mathrm{D}$ and $\delta^{18} \mathrm{O}$ values. This trend is consistent with the results of previous studies, which concluded that the Kashio brine is a mixture of meteoric water and brine with high $\delta \mathrm{D}$ and $\delta^{18} \mathrm{O}$ (Matsubaya et al. 1980; Masuda et al. 1988). The $\delta^{18} \mathrm{O}$ values of the Kashio $\mathrm{B}$ samples showed a wider range than those of the Kashio A samples, although the trends were mutually consistent. The samples collected from the rivers and small springs presented the same isotopic compositions as meteoric waters: the correspondent datapoints were plotted near the intersection of the meteoric water line and the apparent extension of the data trend for the Kashio A and B samples.

The water samples from the Syozu-no-yu mineral spring had a meteoric origin, like the river and small spring waters. The waters from Koshibu and Sansyobo also had a meteoric origin, although these water samples presented lower isotopic ratios than the river and small spring waters. Moreover, the samples from the Nyuya mineral spring had $\delta^{18} \mathrm{O}$ values slightly higher than those of meteoric water.

The above-mentioned trends could also be discerned from the $\delta \mathrm{D}-\mathrm{Cl}$ diagram (Fig. $3 \mathrm{~b}$ ). The data obtained from the Kashio A and B samples showed a linear trend: from meteoric and $\mathrm{Cl}$-free water to high-salinity water. This trend is consistent with the results of previous studies (Matsubaya et al. 1980; Masuda et al. 1988). The Nyuya water showed a small shift in $\delta^{18} \mathrm{O}$ from the meteoric water line (Fig. 3a) and contained 5000-6000 mg/L of $\mathrm{Cl}$. These values are much higher than those measured in the river and small-spring waters. The Sansyobo and Koshibu waters contained even lower amounts of $\mathrm{Cl}$ than the Kashio and Nyuya waters. The Sansyobo water bore $\sim 600 \mathrm{mg} / \mathrm{L}$ of $\mathrm{Cl}$ (more than the river water).

The ${ }^{3} \mathrm{H}$ concentration was measured in 10 samples from Kashio A and B, and one sample each from Sansyobo, Koshibu, and the Shiokawa River (Table 1). The ${ }^{3} \mathrm{H}$ concentration in the water samples from Kashio A and $\mathrm{B}$ varied within 0.13-1.4 TU; moreover, the samples from Kashio B showed higher concentrations than those from Kashio A. Additionally, the Sansyobo and Koshibu samples contained non-measurable amounts of ${ }^{3} \mathrm{H}$. Finally, the ${ }^{3} \mathrm{H}$ concentration in the Shiokawa river water (2.9 $\mathrm{TU})$ was higher than that in Kashio B.

\section{Helium isotopes}

The concentrations and isotope ratios of the noble gases (Table 1 ) varied widely during the sampling period. Figure $4 \mathrm{a}$ shows a plot of ${ }^{3} \mathrm{He} /{ }^{4} \mathrm{He}$ versus ${ }^{4} \mathrm{He} /{ }^{20} \mathrm{Ne}$ obtained from the Kashio A and $\mathrm{B}$ samples. The ${ }^{3} \mathrm{He} /{ }^{4} \mathrm{He}$ values were almost constant or slightly positively correlated with ${ }^{4} \mathrm{He} /{ }^{20} \mathrm{Ne}$, varying between 1.3 and $1.5 \mathrm{Ra}$. These values are significantly higher than the atmospheric one $(1 \mathrm{Ra})$. Meanwhile, the ${ }^{4} \mathrm{He} /{ }^{20} \mathrm{Ne}$ ratio varied widely (between 4.4 and 57.0 in the Kashio A samples, and between 9.6 and 75.2 in the Kashio B samples). In Fig. 4a, the gray dashed lines indicate the mixing between air and the supposed end-members, which contained an upper mantle component $(10 \%, 20 \%$, and $50 \%)$. The ${ }^{3} \mathrm{He} /{ }^{4} \mathrm{He}$ ratios showed in Fig. 4a indicate that the Kashio brine contained a certain amount of mantle-derived noble gas $(15-20 \%)$. The variation in the ${ }^{4} \mathrm{He} /{ }^{20} \mathrm{Ne}$ ratio among the Kashio brine samples seems to be explained by the various contributions of an atmospheric component with a $20 \%$ mantle-component end-member, which apparently derived from the mixing of meteoric water and the KDE (as indicated by $\delta^{18} \mathrm{O}, \delta \mathrm{D}$, and $\mathrm{Cl}$ values) (Fig. 3). However, the $\mathrm{Cl}$ concentrations did not show a linear relationship with the ${ }^{4} \mathrm{He} /{ }^{20} \mathrm{Ne}$ ratio (Fig. 4b), indicating that the variation could not be simply explained by the addition of meteoric water.

The data obtained from the Arima, Takarazuka, and Ishibotoke hot spring samples, categorized as Arima-type by Matsubaya (1981), are also plotted in Fig. 4a (Nagao et al. 1981; Sano and Wakita 1985; Matsumoto et al. 2003; Morikawa et al. 2005; Kusuda et al. 2014). The helium isotope ratios of these samples (5-8 Ra) were even higher than those of the Kashio brine and comparable to those of the upper mantle (Sano and Fischer 2013).

\section{Possible effects of monthly well-water pumping}

We collected several samples during the monthly commercial pumping of water from the Kashio B well. Here, we discuss the possible effect of this pumping on the well water chemistry. Figure 5 shows the $\delta \mathrm{D}$ and $\delta^{18} \mathrm{O}$ variations among the Kashio B samples collected over two stages: within $30 \mathrm{~min}$ from the start of the pumping (or when the pumping was not conducted) and after $>1.5 \mathrm{~h}$ of pumping. The former set of samples was considered to be only marginally affected by commercial pumping and to reflect natural variations; however, the latter set of samples was considered to be affected by pumping and, to possibly reflect artificial variations. Figure 5 shows that the variations among the former set of samples were wider than those among the latter. This suggests that, the impact of natural variations was greater than that of artificial variations due to the drawdown of the spring. Moreover, the trends of variation were consistent for the 

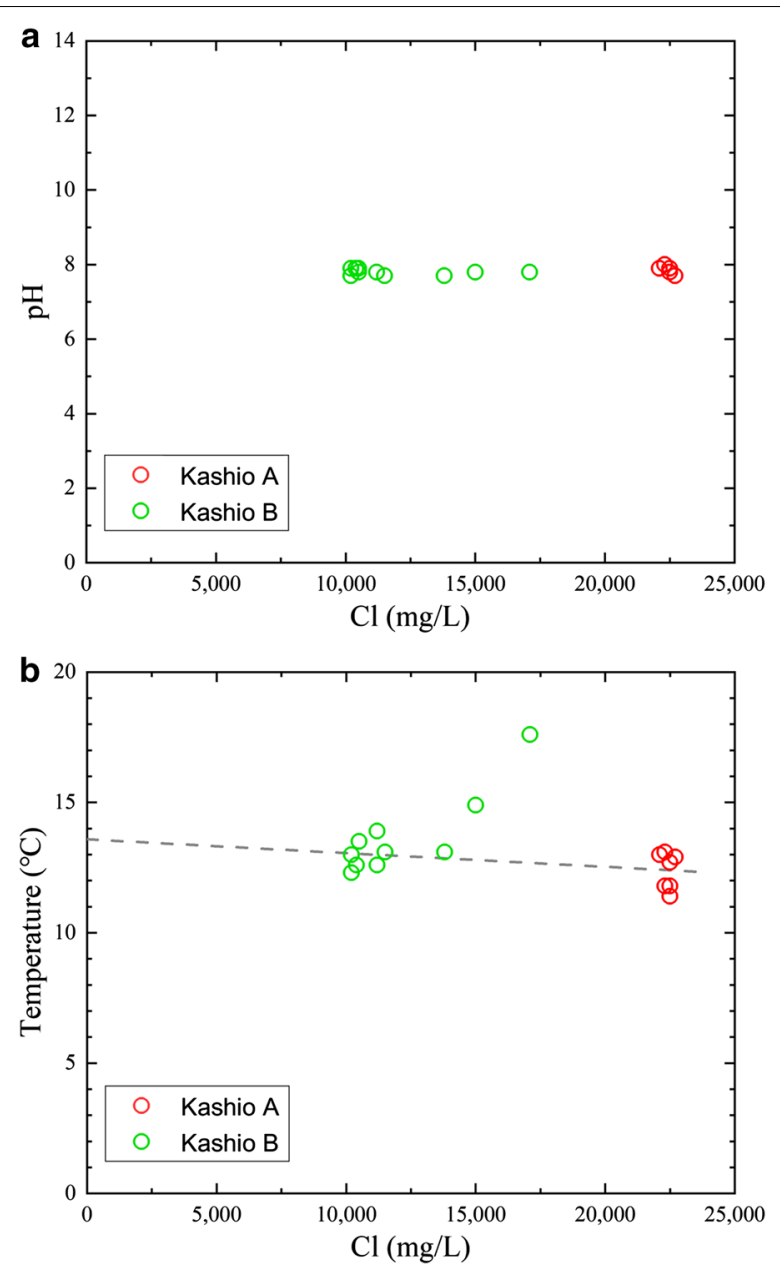

Fig. 2 Relationships between $\mathrm{pH}$ and $\mathrm{Cl}$ concentration and between water temperature and $\mathrm{Cl}$ in water samples from the two wells of the Kashio mineral spring. The $\mathrm{pH}$ was constant over the measurement period whereas the $\mathrm{Cl}$ concentration varied. Water temperature showed a weak negative correlation with $\mathrm{Cl}$ variation, aside from two anomalous values obtained from Kashio B samples (KNK-16-M006 and -M008)

two sets, suggesting that they reflected the same mixing phenomenon of the KDE with meteoric water (Fig. 3). Therefore, we decided to not distinguish these two variations in the present work.

\section{Estimation of the chemical and isotopic compositions of KDE}

Estimated $\mathrm{Cl}$ concentration in the ${ }^{3} \mathrm{H}$-free end-member As indicated in Fig. 3, and in agreement with previous studies (Matsubaya et al. 1980; Masuda et al. 1988), the chemical and isotopic compositions of the Kashio brine can be explained by the mixing of meteoric water and the KDE.
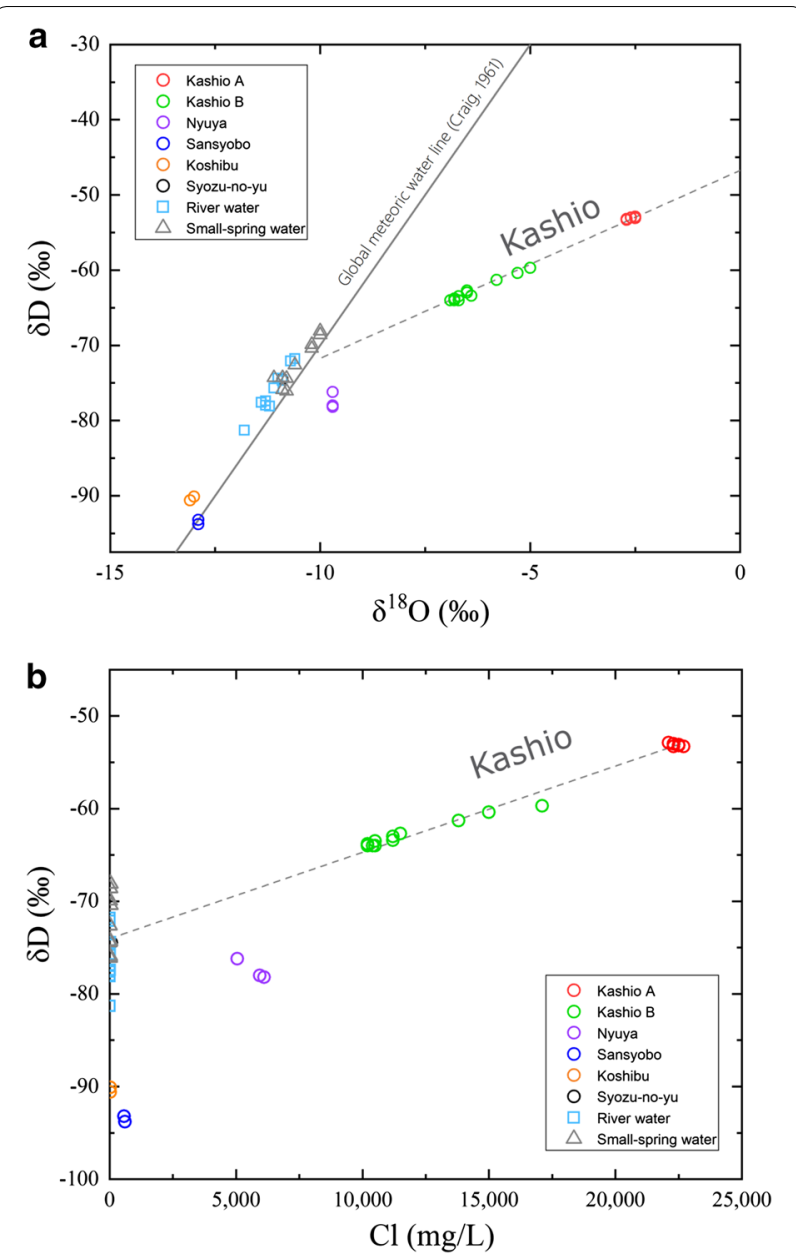

Fig. 3 Relationships between $\delta \mathrm{D}$ and $\delta^{18} \mathrm{O}$ and between $\delta \mathrm{D}$ and $\mathrm{Cl}$ concentration in water samples from mineral springs, rivers, and small springs. $\delta \mathrm{D}, \delta^{18} \mathrm{O}$, and $\mathrm{Cl}$ concentration values obtained from Kashio $A$ and $B$ wells follow a linear trend lines in both plots

Figure 6 shows a plot of the ${ }^{3} \mathrm{H}$ and $\mathrm{Cl}$ concentrations in the Kashio A and B samples. The concentration of ${ }^{3} \mathrm{H}$ varied within $0.13-1.4$ TU. In the Kashio water, ${ }^{3} \mathrm{H}$ concentration was roughly linearly and negatively correlated with $\mathrm{Cl}$ concentration, indicating the mixing of two components: ${ }^{3} \mathrm{H}$-rich meteoric water and ${ }^{3} \mathrm{H}$-poor brine.

Given that ${ }^{3} \mathrm{H}$ originates mainly from the atmosphere and has a short half-life (Clark and Fritz 2000), we can assume that the KDE initially contained no ${ }^{3} \mathrm{H}$ (as observed by Tanaka et al. (1984) in the Arima hot spring). The $\mathrm{Cl}$ concentration in the ${ }^{3} \mathrm{H}$-free end-member was estimated to be $24,000 \pm 2000 \mathrm{mg} / \mathrm{L}(1 \sigma)$ by extrapolating the regression line to 0 TU. Masuda et al. (1988) selected the highest $\mathrm{Cl}$ concentration value measured in their water samples $(670 \mathrm{mEq} / \mathrm{L}$, or $23,800 \mathrm{mg} / \mathrm{L})$ as that of the Kashio brine end-member. Our estimated value is close to that indicated by these authors. 
The ${ }^{3} \mathrm{H}$ concentration in the meteoric water diluting the $\mathrm{KDE}(2.4 \mathrm{TU})$ was calculated by extrapolating the regression line to a concentration of $0 \mathrm{mg} / \mathrm{L}$. This value is similar to that obtained from the Shiokawa River (2.9 TU; KNK-16-M011) and spring samples collected around Mt. Fuji (1.8-2.5 TU; Asai and Koshimizu 2019), whose latitudes are close to that of the Kashio area. Therefore, the meteoric water end-member was considered to be young enough to preserve the original ${ }^{3} \mathrm{H}$ concentration.

\section{Verification of the end-member estimation using an atmospheric noble gas ( $\mathrm{Ne}$ )}

We estimated the $\mathrm{Cl}$ concentration in the ${ }^{3} \mathrm{H}$-free endmember to be $\sim 24,000 \mathrm{mg} / \mathrm{L}$. Afterward, we wanted to determine whether this end-member coincided with the $\mathrm{KDE}$ or not. One concern was that, if we sampled the Kashio brine long after the mixing of ${ }^{3} \mathrm{H}$-bearing meteoric water, the ${ }^{3} \mathrm{H}$ concentration in each sample would have been underestimated, due to the decay of ${ }^{3} \mathrm{H}$. In this case, the regression line showed in Fig. 6 would appear lower than it actually is, and both the $\mathrm{Cl}$ concentration in the ${ }^{3} \mathrm{H}$-free end-member and the ${ }^{3} \mathrm{H}$ concentration in the $\mathrm{Cl}$-poor end-member would have been underestimated. However, the ${ }^{3} \mathrm{H}$ concentration in the $\mathrm{Cl}$-poor end-member in Fig. 6 (2.4 TU) was similar to that in the nearby river water $(2.9 \mathrm{TU})$. We infer that our sampling did not take place long after the mixing of the ${ }^{3} \mathrm{H}$-bearing meteoric water and ${ }^{3} \mathrm{H}$-free end-member. In this case, the mixing line in Fig. 6 can be considered appropriate, indicating a $\mathrm{Cl}$ concentration of $\sim 24,000 \mathrm{mg} / \mathrm{L}$ in the ${ }^{3} \mathrm{H}$-free end-member.

Another concern was that the ${ }^{3} \mathrm{H}$-free end-member consisted of a mix of $\mathrm{KDE}$ and old ${ }^{3} \mathrm{H}$-free meteoric water (characterized by a lower $\mathrm{Cl}$ concentration). In such a case, the $\mathrm{Cl}$ concentration in the KDE would have been $>24,000 \mathrm{mg} / \mathrm{L}$. Hereafter, we discuss the possibility of the contribution of old meteoric water in the Kashio A samples in terms of atmospheric noble gas. As the $\mathrm{Cl}$ concentration in the Kashio A brine samples remained almost constant during the sampling period (Table 1, Fig. 3), the contribution rate of meteoric water, regardless of it being fresh or old, was also considered to be constant. Nevertheless, the concentration of ${ }^{20} \mathrm{Ne}$ (an atmospheric noble gas) in the Kashio A samples varied greatly: from $8 \times 10^{-9}$ to $6 \times 10^{-8} \mathrm{~cm}^{3} \mathrm{STP} / \mathrm{gH}_{2} \mathrm{O}$ (Table 1 ). These values were consistently lower than those typical of airsaturated water $\left(1.7-2 \times 10^{-7} \mathrm{~cm}^{3} \mathrm{STP} / \mathrm{gH}_{2} \mathrm{O}\right.$ at $\left.0-20^{\circ} \mathrm{C}\right)$. These results indicate that the $\mathrm{Ne}$ concentrations in the Kashio A samples were not affected by water mixing, but rather by another process. The concentration of noble gases in the sampled water can be altered by air
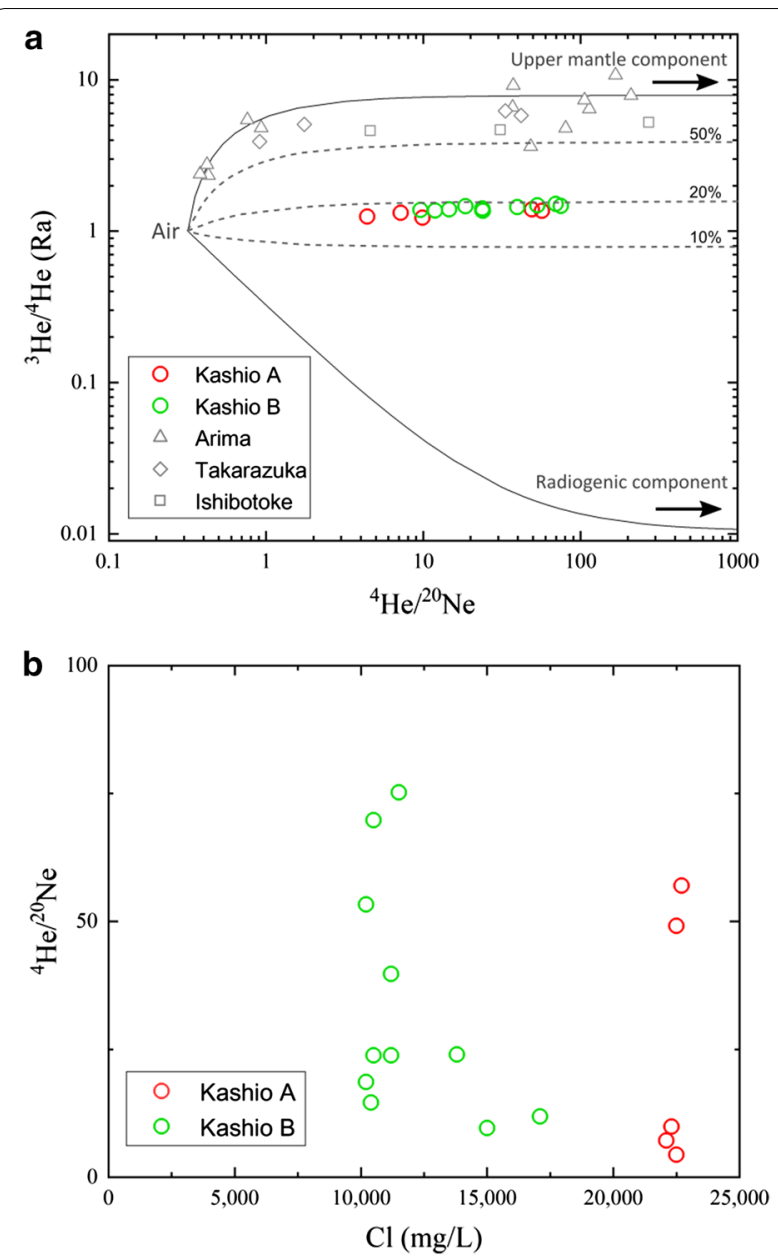

Fig. 4 Relationship between ${ }^{3} \mathrm{He} /{ }^{4} \mathrm{He},{ }^{4} \mathrm{He} /{ }^{20} \mathrm{Ne}$, and $\mathrm{Cl}$ in water samples from the Kashio $A$ and $B$ wells. a Relationship between helium isotope ratio $\left({ }^{3} \mathrm{He} /{ }^{4} \mathrm{He}\right)$ and ${ }^{4} \mathrm{He} /{ }^{20} \mathrm{Ne}$. The two solid curves indicate the mixing lines between the upper mantle and radiogenic components and air, respectively. Three gray dashed lines indicate the mixing between air and the supposed end-member containing the upper mantle component partially (10\%, 20\%, and 50\%). For comparison, data from the previous studies of Arima, Takarazuka, and Ishibotoke are also plotted (Nagao et al. 1981; Sano and Wakita 1985; Matsumoto et al. 2003; Morikawa et al. 2005; Kusuda et al. 2014). b ${ }^{4} \mathrm{He} /{ }^{20} \mathrm{Ne}$ versus $\mathrm{Cl}$ diagram. No linear relationship is observed between these variables

contamination during sampling or by decompressioninduced degassing during pumping. The Kashio A samples were collected by using a hand pump placed on the well. This instrument can cause air contamination or the degassing of dissolved gases from water during sampling. By determining which process occurred, it would be possible to estimate the original ${ }^{20} \mathrm{Ne}$ concentration in the Kashio A brine. We determined the contribution of the meteoric water contained in the brine, since meteoric 


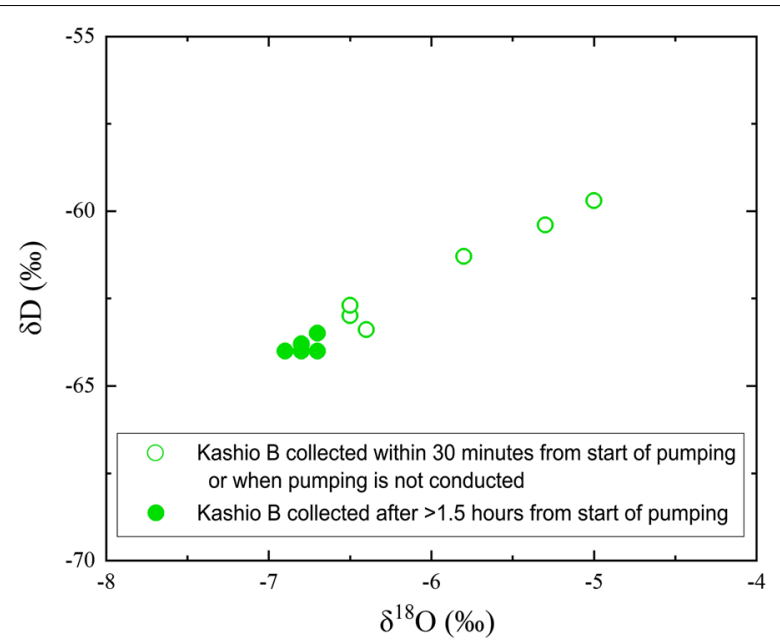

Fig. 5 Relationship between $\delta D$ and $\delta^{18} \mathrm{O}$ in water samples from the Kashio $\mathrm{B}$ well. The data is plotted in two categories: within $30 \mathrm{~min}$ from the start of the commercial pumping (or when the pumping was not conducted) (open circles) and after $>1.5 \mathrm{~h}$ of pumping (filled circles). Variation of the former is wider than that of the latter

groundwater is expected to maintain its ${ }^{20} \mathrm{Ne}$ concentration in atmospheric equilibrium regardless of its recharge period due to chemical inertness.

Figure 7 shows the data of the Kashio A samples (red closed circles) and the calculation results of the ${ }^{4} \mathrm{He} /{ }^{20} \mathrm{Ne}$ ratio and ${ }^{20} \mathrm{Ne}$ concentration obtained by considering the occurrence of air contamination in the original Kashio A sample (gray solid line). The calculations were performed under the assumption that up to $4.0 \times 10^{-2} \mathrm{~cm}^{3}$ STP of air was added to $10 \mathrm{~g}$ of KNK-16-M005 water sample (the most ${ }^{20} \mathrm{Ne}$-depleted). The variations in the ${ }^{4} \mathrm{He} /{ }^{20} \mathrm{Ne}$ ratio and ${ }^{20} \mathrm{Ne}$ concentration in the Kashio A samples are well explained by the solid line, indicating how the variations among the Kashio A samples can be explained by the occurrence of air contamination in KNK-16-M005: it is quite likely that the contamination of a small amount of air (e.g., $0.04 \mathrm{~cm}^{3} \mathrm{STP} / 10 \mathrm{~g} \mathrm{H}_{2} \mathrm{O}$ ) occurred during sampling. On the other hand, if degassing occurred during sampling, the concentration of ${ }^{4} \mathrm{He}$ would have been expected to decrease faster than that of ${ }^{20} \mathrm{Ne}$, due to mass fractionation: the ratio of ${ }^{4} \mathrm{He} /{ }^{20} \mathrm{Ne}$ should have decreased with ${ }^{20} \mathrm{Ne}$ concentration. However, the data obtained from the Kashio A water samples did not indicate such a trend (Fig. 7). Considering our results, the variation in noble gas composition among the Kashio A samples was better explained by air contamination, rather than by degassing.

If air contamination caused variations in the noble gas concentration in the Kashio A samples, it would

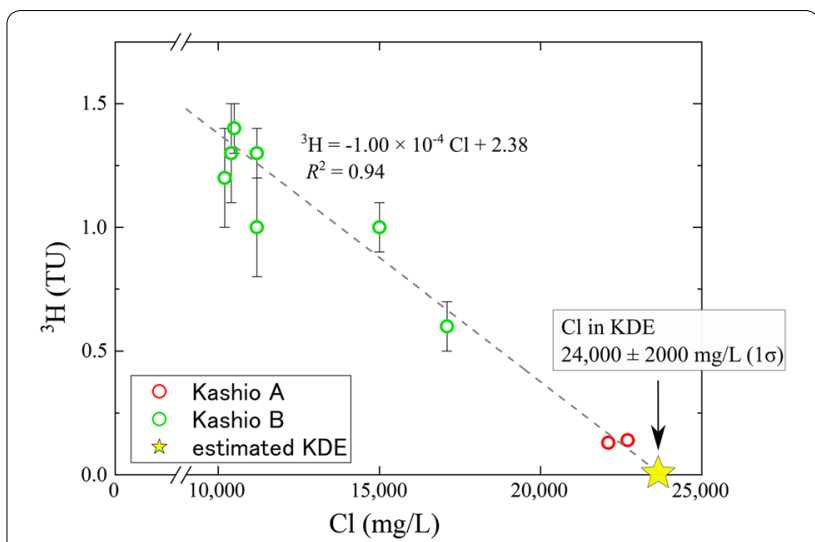

Fig. 6 Negative linear relationship between ${ }^{3} \mathrm{H}$ and $\mathrm{Cl}$ concentrations in the Kashio $\mathrm{A}$ and $\mathrm{B}$ water samples. Assuming that $\mathrm{KDE}$ has no ${ }^{3} \mathrm{H}$, the $\mathrm{Cl}$ concentration of KDE was estimated to be $24,000 \pm 2000 \mathrm{mg} / \mathrm{L}$. $\left[R^{2}\right.$ correlation coefficient]

be expected that the most ${ }^{20} \mathrm{Ne}$-depleted sample (KNK-16-M005) would best preserve the original ${ }^{20} \mathrm{Ne}$ concentration in the Kashio A samples. The ${ }^{20} \mathrm{Ne}$ concentration in the KNK-16-M005 sample $\left(8 \times 10^{-9} \mathrm{~cm}^{3}\right.$ $\mathrm{STPNe} / \mathrm{gH}_{2} \mathrm{O}$ ) was found to correspond to $\sim 5 \%$ of the ${ }^{20} \mathrm{Ne}$ dissolved in air-saturated water. Hence, the contribution of the meteoric water contained in the Kashio A brine would have been $<5 \%$.

In terms of ${ }^{3} \mathrm{H}$ and $\mathrm{Cl}$ concentrations, the Kashio $\mathrm{A}$ brine was very similar to the ${ }^{3} \mathrm{H}$-free end-member brine (Fig. 6). From the above discussion on atmospheric ${ }^{20} \mathrm{Ne}$, it can be concluded that the Kashio A brine contains little amount of meteoric water (fresh and ${ }^{3} \mathrm{H}$-bearing or old and ${ }^{3} \mathrm{H}$-free). In other words, the ${ }^{3} \mathrm{H}$-free end-member containing $24,000 \mathrm{mg} / \mathrm{L}$ of $\mathrm{Cl}$ (as deduced from Fig. 6) also bears little amount of meteoric water and coincides with the KDE.

\section{Chemical and isotopic composition of KDE}

Figure $8 \mathrm{a}-\mathrm{h}$ shows the chemical compositions of the Kashio A and B samples; the $\mathrm{Cl}$ concentration (horizontal axes) is plotted against the $\mathrm{Na}, \mathrm{K}, \mathrm{Mg}, \mathrm{Ca}, \mathrm{HCO}_{3}$, $\mathrm{SO}_{4}, \mathrm{Li}$, and $\mathrm{Br}$ concentrations (vertical axes). The cations (i.e., $\mathrm{Na}, \mathrm{K}, \mathrm{Mg}, \mathrm{Ca}$, and $\mathrm{Li}$ ) and $\mathrm{Br}$ showed positive linear relationships with $\mathrm{Cl}$, indicating a two-component mixing system between the cation- and halogen-rich $\mathrm{KDE}$ and the meteoric water bearing low ion concentrations (as also suggested by the oxygen and hydrogen isotopic data in Fig. 3). The $\mathrm{HCO}_{3}$ and $\mathrm{SO}_{4}$ concentrations decreased under increasing $\mathrm{Cl}$, likely reflecting the depletion of $\mathrm{HCO}_{3}$ and $\mathrm{SO}_{4}$ in the KDE. A depletion of $\mathrm{SO}_{4}$ was previously observed in the Arima and Takarazuka hot springs (Matsubaya et al. 1973; Kusuda et al. 
2014); however, these hot spring waters exhibited higher dissolved inorganic carbon (DIC) concentrations. Meanwhile, the Kashio brine did not bear free $\mathrm{CO}_{2}$ and the KDE was characterized by a lack of DIC.

The chemical and isotopic compositions of the KDE were estimated by extrapolating the linear relationships to the $\mathrm{Cl}$ concentration of $24,000 \mathrm{mg} / \mathrm{L}$. The estimation results are shown in Table 2. The charge balance of the major ions in the estimated KDE was $-3.8 \%$, falling within a reasonable range.

As discussed above, the meteoric water diluting the $\mathrm{KDE}$ was supposed to contain a greater amount of $\mathrm{HCO}_{3}$ and $\mathrm{SO}_{4}$ than $\mathrm{KDE}$. The concentrations of these two components were estimated to be $220 \mathrm{mg} / \mathrm{L}$ and $18 \mathrm{mg} / \mathrm{L}$, respectively, and calculated by extrapolating the regression lines to a $\mathrm{Cl}$ concentration of $0 \mathrm{mg} / \mathrm{L}$. The concentration of $\mathrm{SO}_{4}$ was found to be higher than in the other mineral springs within the study area, and similar to those of the Koshibu River $(\sim 15 \mathrm{mg} / \mathrm{L})$ and small springs (8-39 mg/L). Meanwhile, the $\mathrm{HCO}_{3}$ concentration in the diluting water was much higher than that in the river and small spring, but close to that in the Koshibu mineral spring, whose water gushes from limestone of the Chichibu belt. Yamada et al. (1973) pointed out the possibility of the host rock affecting the chemistry of water flowing through it. Consequently, the meteoric water diluting the KDE could be affected by the limestone, as in the case of Koshibu mineral spring.

Figure $8 \mathrm{i}$ and $\mathrm{j}$ shows each a plot of $\delta \mathrm{D}$ versus $\mathrm{Cl}$ and $\delta^{18} \mathrm{O}$ obtained from the Kashio A and B samples, respectively. The $\delta \mathrm{D}$ and $\delta^{18} \mathrm{O}$ of the KDE were estimated to be $-52 \%$ and $-2 \%$, respectively.

The $\mathrm{pH}$ of the Kashio brine was almost constant at $\sim 7.8$ (Fig. 2a), suggesting that the two mixing waters had similar $\mathrm{pH}$ values. This value is close to those of the river (8-9) and small spring (7.6-8.5) waters in the study area. The water temperature was also constant, but seemed to have a slight negative correlation with $\mathrm{Cl}$ concentration (Fig. 2b). By extrapolating the regression line to $24,000 \mathrm{mg} / \mathrm{L}$ of $\mathrm{Cl}$, the temperature of the $\mathrm{KDE}$ was estimated to be $\sim 12{ }^{\circ} \mathrm{C}$.

\section{Origin of KDE}

\section{Possibility of slab-derived fluids}

There are various hypotheses on the origin of the Kashio brine (Nakamura and Maeda 1958; Hashizume 1984; Takamatsu et al. 1986; Kazahaya et al. 2014; Muramatsu et al. 2016). In this section, we discuss the origin of the $\mathrm{KDE}$ using the estimated $\delta \mathrm{D}, \delta^{18} \mathrm{O}$, its water chemistry, and the available geological data. Groundwater can originate from meteoric water (present or fossil), seawater, magmatic water, or slab-derived fluids. Each of these cases is discussed below.

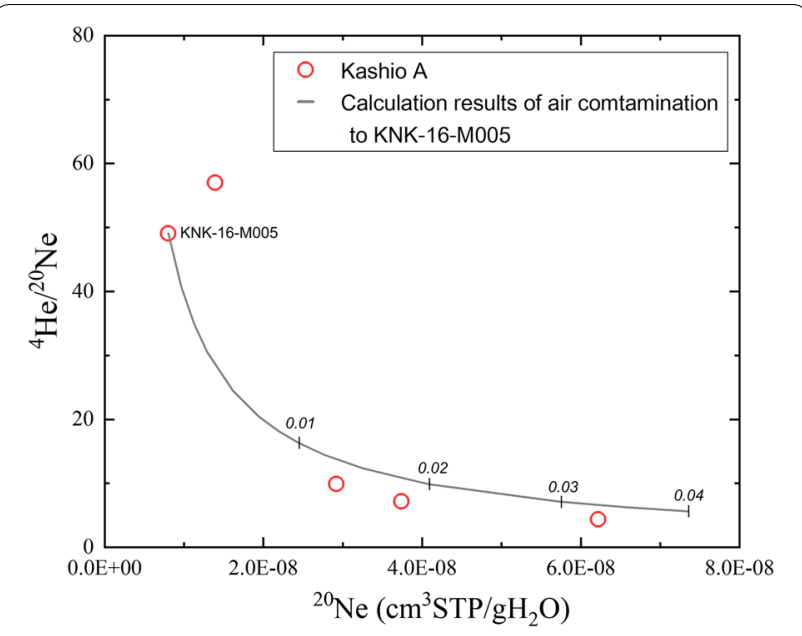

Fig. 7 Relationship between the ${ }^{4} \mathrm{He} /{ }^{20} \mathrm{Ne}$ ratio and ${ }^{20} \mathrm{Ne}$ concentrations in the Kashio A samples. The gray solid curve indicates the trend by adding air to the sample KNK-16-M005 up to $4.0 \times 10^{-2}$ $\mathrm{cm}^{3}$ STP per $10 \mathrm{~g}$ of sample water, based on the concentration of $\mathrm{He}$ and $\mathrm{Ne}$ and their stable isotope ratio of air (Ozima and Podosek 2002). Numbers along the curve indicate the amount of air added $\left(\mathrm{cm}^{3}\right.$ STP per $10 \mathrm{~g}$ of sample water). The variation of ${ }^{4} \mathrm{He} /{ }^{20} \mathrm{Ne}$ ratio and ${ }^{20} \mathrm{Ne}$ concentration in Kashio A samples is clearly explained by air contamination

\section{(a) Meteoric water}

The $\delta^{18} \mathrm{O}$ value of the KDE was significantly different from that of local meteoric water (Fig. 9). It has been hypothesized that meteoric water infiltrates into underground spaces and accumulates ${ }^{18} \mathrm{O}$ through isotope exchange reactions with rocks (Craig 1963). However, this idea cannot explain the high salinity of the KDE. River water in the study area contains less than a few $\mathrm{mg} / \mathrm{L}$ of $\mathrm{Cl}$ (Table 1 ). The $\mathrm{Cl}$ concentration in the KDE is $\sim 10,000$ times that value. Such an increase in concentration is not reasonable, because the average annual rainfall in the area reaches $1000 \mathrm{~mm}$ (Japan Meteorological Agency 2019). Notably, Cl-rich rocks (e.g., halite) have not been found in the area; therefore, the KDE cannot have originated from meteoric water.

\section{(b)Seawater}

$\delta^{18} \mathrm{O}$ and $\delta \mathrm{D}$ are close to nearly zero in current seawater, reflecting the standard oxygen and hydrogen isotope ratios. Although the $\delta^{18} \mathrm{O}$ of the $\mathrm{KDE}$ is close to $0, \delta \mathrm{D}$ is much lower than in current seawater. Fossil seawater and oilfield brine often has a lighter hydrogen isotope ratio than current seawater (Kato and Kajiwara 1986; Kato et al. 2000; Muramatsu et al. 2012). However, the $\delta D$ of fossil seawater and oilfield brine is approximately $-20 \%$ o at minimum, and an isotope ratio shift up to $-50 \%$ o has not been reported yet. 


\section{(c) Magmatic water}

First, the possibility of magmatic water origin is discussed in geological terms. The study area is non-volcanic and the nearest Quaternary volcano, Mt. Yatsugatake, is located $>50 \mathrm{~km}$ away from the Kashio mineral spring (Fig. 1a). The geothermal gradient measured at the nearest deep borehole is $29 \mathrm{~K} / \mathrm{km}$, which is relatively close to the average value in Japan (Tanaka et al. 1999). Therefore, the impact of current volcanism is not a reasonable explanation for the origin of the KDE. The Yamaga hot spring in Oita Prefecture, southwestern Japan, may have originated from residual magmatic water linked to ancient (Tertiary?) volcanism (Sakai et al. 2013). It is not clear whether such old magmatic water was at the origin of the KDE. Felsite dykes were observed at the outcrops of the MTL located $(\sim 20 \mathrm{~km}$ to the north of the Kashio mineral spring) and their $\mathrm{K}-\mathrm{Ar}$ ages were determined to vary between 12.3 and 15.6 Ma (Takagi et al. 1991). Although the provenance of ancient magmatic water from these Miocene dykes cannot be entirely ruled out, we consider it unlikely, because they were not observed at any outcrop near the Kashio mineral spring (Shibata and Takagi 1988).

Afterwards, the possible magmatic origin of the water is discussed based on the hydrogen and oxygen isotope ratios. Andesitic magmatic water has a characteristic isotopic composition: $\delta \mathrm{D}$ comprised between $-10 \%$ and $-30 \%$, and $\delta^{18} \mathrm{O}$ between $+5 \%$ and $+10 \%$ (Giggenbach 1992). The isotopic composition of the KDE is obviously different from that of magmatic water values. Assuming magmatic water at the origin of the $\mathrm{KDE}$, a shift in the isotope ratio in water would be expected.

It is known that oxygen isotope exchange reactions occur when water is in contact with minerals (Kawabe 1978; Matsuhisa et al. 1979). According to laboratory experiments, quartz, K-feldspar, and calcite concentrate ${ }^{18} \mathrm{O}$ below $800{ }^{\circ} \mathrm{C}$, whereas muscovite and anorthite concentrate ${ }^{18} \mathrm{O}$ below $400{ }^{\circ} \mathrm{C}$ (Faure 1977), causing a decrease of $\delta^{18} \mathrm{O}$ in water. Minerals concentrate a greater amount of ${ }^{18} \mathrm{O}$ at lower temperatures (Faure 1977). On the other hand, below $800{ }^{\circ} \mathrm{C}$, heavy hydrogen isotope generally accumulates in water rather than in minerals. Water concentrates a greater amount of D at lower temperatures (Suzuoki and Epstein 1976).

As noted above, such a reaction is expected to cause a decrease in $\delta^{18} \mathrm{O}$ and an increase in $\delta \mathrm{D}$, shifting the isotopic composition of water toward the upper left part of the $\delta \mathrm{D}-\delta^{18} \mathrm{O}$ diagram. The isotopic composition of the $\mathrm{KDE}$ is plotted in the lower left part of the magmatic water plot (Fig. 9). The $\delta \mathrm{D}$ value of the KDE unlikely derived from that of magmatic water.

\section{(d) Slab-derived fluids}

In the present study, with the term "slab-derived fluids" we refer to deep-seated water originating from the dehydration of hydrous minerals in subducted slabs. The existence of slab-derived fluids has been discussed from the standpoint of thermodynamics (Hacker 2008), geophysics (Obara 2002), and geochemistry (Amita et al. $2005,2014)$. Although the $\delta \mathrm{D}$ and $\delta^{18} \mathrm{O}$ of slab-derived fluids have not been directly observed, Kusuda et al. (2014) numerically predicted variations in them with the slab depth based on the mineral composition model of a subducted slab, the equilibrium equations between each mineral and water, and the thermal profile estimated along the slab surface for the Philippine Sea (southwestern Japan) and the Pacific (northeastern Japan) slabs. The depth of the Philippine Sea slab surface beneath the Arima hot spring was estimated to be $50-70 \mathrm{~km}$, with a relatively large uncertainty (Nakajima and Hasegawa 2007; Hirose et al. 2008). Kusuda et al. (2014) suggested that the slab-derived fluid at such a depth should have an isotopic composition similar to that of the deep brine of the Arima hot spring, which was geochemically estimated (Matsubaya et al. 1973; Tanaka et al. 1984; Masuda et al. 1985). According to their calculation results, the isotopic composition of the slab-derived fluid should vary with depth. Hereafter, we discuss this topic based on the model in Kusuda et al. (2014).

The Philippine Sea slab is subducted beneath the Kashio area. The estimated isotopic composition of the KDE cannot be explained by the calculation results obtained for southwestern Japan (Kusuda et al. 2014) (Fig. 9). However, it can be explained by considering an isotope exchange reaction between the water and the minerals, as discussed above: the isotopic composition of the KDE in the $\delta \mathrm{D}-\delta^{18} \mathrm{O}$ diagram might be explained by a leftward isotopic shift starting from the calculation results of Kusuda et al. (2014) at a depth of 80-100 km (yellow arrow in Fig. 9). Based on the results of Kusuda et al. (2014), it appears that no substantial hydrogen isotope exchange reactions occurred.

Assuming that the isotope exchanges described above led to the isotopic composition of the KDE starting from a slab-derived fluid, the $\delta^{18} \mathrm{O}$ of water should have decreased by $\sim 10 \%$. It is important to consider whether this relatively large shift is reasonable. Clayton et al. (1972) predicted a $\delta^{18} \mathrm{O}$ difference of $11.4 \%$ between quartz and water at oxygen isotopic equilibrium and under $P-T$ conditions of $1 \mathrm{kbar}$ and $240{ }^{\circ} \mathrm{C}$. Matsuhisa et al. (1978) suggested that the $\delta^{18} \mathrm{O}$ difference between quartz and water would be $\sim 9 \%$ at $16 \mathrm{kbar}$ and $250{ }^{\circ} \mathrm{C}, \sim 2.8 \%$ between albite and water at $10-12 \mathrm{kbar}$ and $400{ }^{\circ} \mathrm{C}$, and $\sim 0.5 \%$ between anorthite and water at 

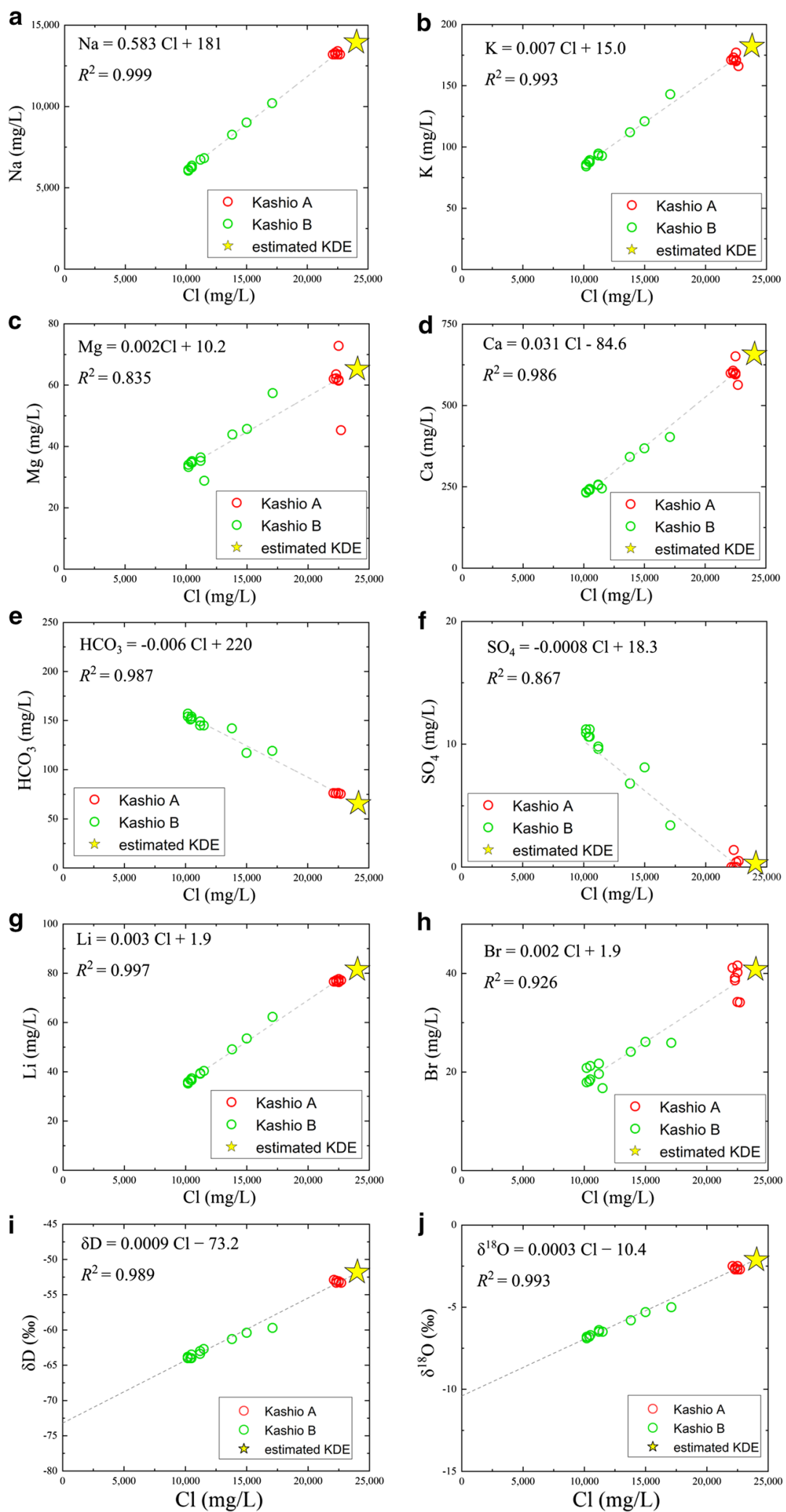

Fig. 8 Linear relationships between $\mathrm{Cl}$ and other atomic constituents. a $\mathrm{Na}, \mathbf{b ~ K}, \mathbf{c ~ M g}, \mathbf{d ~ C a}, \mathbf{e ~} \mathrm{HCO}_{3}, \mathbf{f} \mathrm{SO}_{4}, \mathbf{g ~ L i}, \mathbf{h ~ B r}, \mathbf{i} \delta \mathrm{D}$, and $\mathbf{j} \delta^{18} \mathrm{O}$ in water samples from the two Kashio wells. Also shown is the estimated chemical composition of KDE. ( $R^{2}$ correlation coefficient) 


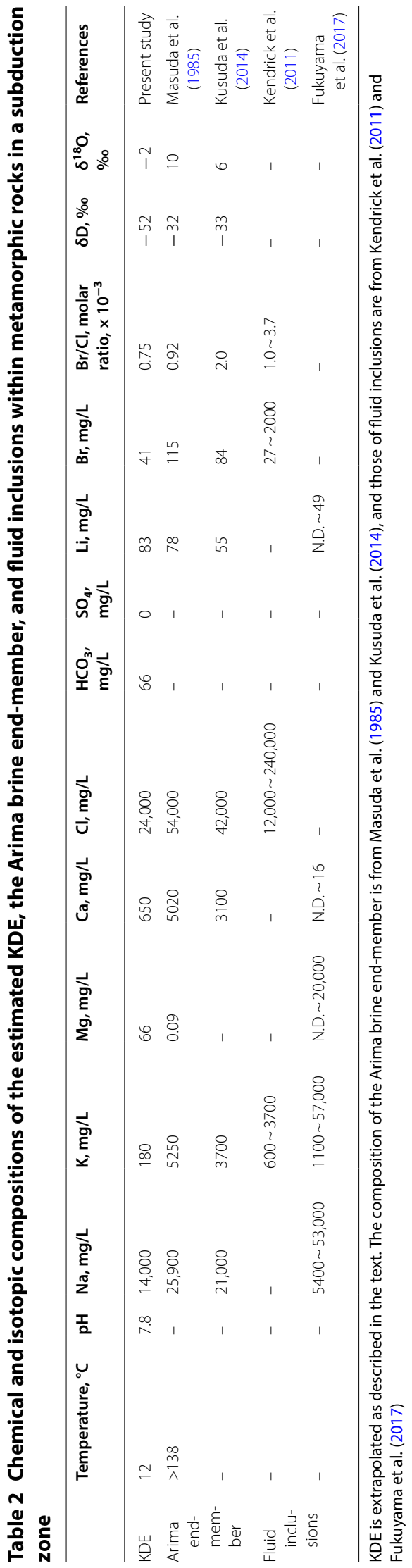




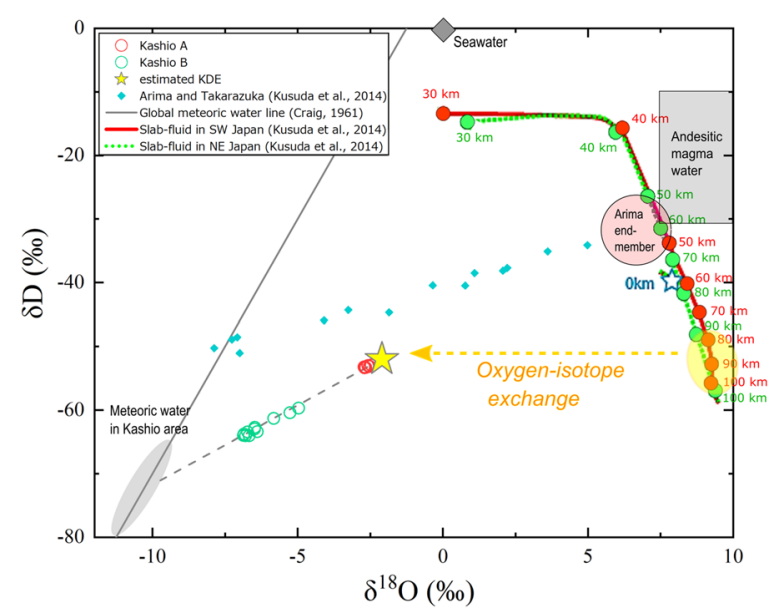

Fig. 9 Comparison of the isotopic compositions of KDE and those of the Arima and Takarazuka waters with the calculated, slab-derived fluid from previous research. Red and green solid lines show the calculation results of $\delta D$ and $\delta^{18} O$ in water dehydrated from a subducted slab as a function of depth for the Philippine Sea and Pacific slabs, respectively (Kusuda et al. 2014). The estimated KDE might be interpreted as a slab-derived fluid which originated from dehydration at 80-100 km in depth of the Philippine Sea slab (SW Japan, red solid curve) and its isotope exchange reactions (mainly oxygen) with minerals (yellow arrow). Andesitic magma water and Arima end-member is from Giggenbach (1992) and Kusuda et al. (2014), respectively

2 kbar and $400{ }^{\circ} \mathrm{C}$. These $\delta^{18} \mathrm{O}$ differences between minerals and water become greater at lower temperatures (Faure 1977). Generally, metamorphic rocks and granite have $\delta^{18} \mathrm{O}$ values comprised between $+10 \%$ and $+25 \%$ o and equal to $\sim 10 \%$, respectively (Sakai and Matsuhisa 1996). Therefore, we infer that a $10 \%$ decrease in $\delta^{18} \mathrm{O}$ could occur under adequately low temperatures and water-rock ratios. In contrast to $\delta^{18} \mathrm{O}$, the $\delta \mathrm{D}$ of the KDE was only slightly different from that of a slab-derived fluid at $80-100 \mathrm{~km}$ depth, possibly suggesting a small impact of the hydrogen isotope exchange in minerals. From the above discussion, we conclude that the isotopic composition of the KDE can be explained by a slab-derived fluid and its isotope exchange reaction with minerals.

\section{Comparison between KDE and dehydration-origin fluid inclusions in the subduction zone}

Next, we discuss whether the chemical composition of the KDE is reasonable by comparing it to that of a slab-derived fluid. Although the chemical composition of slab-derived fluids has never been directly measured, that of fluid inclusions trapped in metamorphic rocks located in subduction zones has been analyzed in some studies (Kendrick et al. 2011; Kawamoto et al. 2013; Fukuyama et al. 2017) (Table 2). The fluid inclusions analyzed in these studies were rich in highly mobile elements (Kaasalainen and Stefánsson 2012), such as $\mathrm{Cl}$ (between $\sim 10,000$ and $\sim 100,000 \mathrm{ppm}$ ), Li (up to $\sim 50 \mathrm{ppm}$ ), and B (up to $\sim 770 \mathrm{ppm}$ ), and were considered to have originated through dehydration in subduction zones. Kusuda et al. (2014) suggested that the chemical composition of the Arima end-member is in good agreement with this type of fluid inclusions (Kendrick et al. 2011; Kawamoto et al. 2013). Based on these reports, we infer that fluid inclusions can give a rough indication of the chemical composition of slab-derived fluids. The cation concentrations in fluids, however, can be easily altered due to chemical reactions with minerals that are in contact with the fluid, suggesting that cations might not act as indicators. The halogen concentrations are less subject to fluid-rock reactions because rock-forming minerals generally do not contain much halogens.

Kendrick et al. (2011) reported large variation of the $\mathrm{Cl}$ and $\mathrm{Br}$ concentrations in the fluid inclusions of metamorphic rocks in subduction zones (Table 2): they varied between 12,000-240,000 $\mathrm{mg} / \mathrm{L}$ and $27-2000 \mathrm{mg} / \mathrm{L}$, respectively. The $\mathrm{Cl}$ and $\mathrm{Br}$ concentrations in the $\mathrm{KDE}$ were within the range of the results obtained by Kendrick et al. (2011) $(24,000 \mathrm{mg} / \mathrm{L}$ and $41 \mathrm{mg} / \mathrm{L}$, respectively). The ratio of these halogen concentrations $(\mathrm{Br} /$ $\mathrm{Cl}$ ) in the KDE was $0.75 \times 10^{-3}$ (molar ratio). This value is close to those reported by Kendrick et al. (2011) $\left(1.0 \times 10^{-3} \sim 3.7 \times 10^{-3}\right)$, and consistent with the prediction that the $\mathrm{Br} / \mathrm{Cl}$ ratio of the slab-derived fluid would be lower than that of seawater $\left(1.6 \times 10^{-3} ; \mathrm{Li} 1982\right)$, owing to the difference in the ionic radii of the $\mathrm{Br}$ and $\mathrm{Cl}$ anions (John et al. 2011).

Therefore, in terms of halogen concentrations and ratios, it would make sense to consider the KDE a slabderived fluid. As mentioned above, the ${ }^{3} \mathrm{He} /{ }^{4} \mathrm{He}$ ratio of the Kashio brine is significantly higher than that of air: this brine is considered to contain a mantle-derived component to some extent, which is concordant with the possibility of a slab-derived fluid origin.

For reference, we compared the cations of the KDE and fluid inclusions. The concentrations of $\mathrm{Na}, \mathrm{K}, \mathrm{Mg}$, and $\mathrm{Li}$ in the KDE are within the order of magnitude of those measured by Kendrick et al. (2011) and Fukuyama et al. (2017). The Ca concentration in the KDE is much higher than in the fluid inclusions, possibly due to the influence of a solution of Ca-bearing minerals (e.g., anorthite and carbonates).

We conclude that the isotopic composition of the KDE may be explained by its origin as a slab-derived fluid and its isotopic exchange with minerals in terms of isotopic composition, and the chemical composition is likely consistent with that of slab-derived fluid inclusions. 


\section{Difference between KDE and Arima end-member}

As mentioned above, Matsubaya et al. (1980) and Matsubaya (1981) assumed that the Kashio brine has the same end-member as the Arima brine, mainly based on the trends of $\delta \mathrm{D}$ and $\delta^{18} \mathrm{O}$. However, the estimated chemical and isotopic compositions of the KDE are significantly different from those of the Arima end-member.

Table 2 shows the chemical and isotopic compositions of the KDE and end-member of the Arima brine (Masuda et al. 1985; Kusuda et al. 2014). One interesting feature is that the concentrations of $\mathrm{Na}, \mathrm{K}, \mathrm{Ca}, \mathrm{Cl}$, and $\mathrm{Br}$ in the $\mathrm{KDE}$ are $\leq 50 \%$ compared to those of the Arima end-member, whereas the KDE presented higher concentrations of $\mathrm{Mg}$ and $\mathrm{Li}$ than the Arima end-member. As discussed in the section about atmospheric noble gas, the KDE is likely to contain little amount of meteoric water. Contrary to what was predicted in previous studies, the KDE cannot be interpreted as an Arima endmember diluted by meteoric water. In fact, differences in chemical and isotopic compositions, particularly in $\mathrm{Cl}$ concentration and $\delta \mathrm{D}$, indicate that the $\mathrm{KDE}$ and the Arima end-member are essentially different from each other. Considering the wide range of chemical compositions of the fluid inclusions (Table 2), we infer that slab-derived fluids may present variations in chemical composition. The different chemical composition of the KDE and the Arima end-member may reflect these variations. Kusuda et al. (2014) indicated the possibility that the oxygen and hydrogen isotope ratios in slab-derived fluids may vary with the depth of dehydration (Fig. 9). As discussed above, the difference in $\delta^{18} \mathrm{O}$ between the KDE and the Arima end-member may be explained by an oxygen isotope exchange (Fig. 9). Following the model of Kusuda et al. (2014), the significant lower $\delta D$ in the KDE may imply that its dehydration depth is greater than that of the Arima end-member. Meanwhile, the depth of the Philippine Sea slab below Kashio ( $50 \mathrm{~km}$; Fig. 1A) is not much different from the depth of that below the Arima hot spring, i.e., 50-70 km (Nakajima and Hasegawa 2007; Hirose et al. 2008).

Another interesting feature is the carbon depletion in the KDE. Masuda et al. (1985) suggested that the Arima end-member initially bears a significant amount of $\mathrm{CO}_{2}$, which is boiled off before surfacing. Kawamoto et al. (2013) reported $\mathrm{CO}_{2}$-bearing saline fluid inclusions in spinel-harzburgite xenoliths collected from 1991 Pinatubo pumice deposits and suggested the hydration of the forearc and uppermost mantle by slab-derived $\mathrm{CO}_{2}$-bearing saline fluids. Considering these previous studies, slab-derived fluid is likely to bear $\mathrm{CO}_{2}$ (or DIC). However, the Kashio brine contains little $\mathrm{HCO}_{3}$ and no free $\mathrm{CO}_{2}$. The cause of this is unknown and will be the subject of future studies.
The third interesting feature is the helium isotope ratio. According to previous studies, brine samples from the Arima hot spring possessed a ${ }^{3} \mathrm{He} /{ }^{4} \mathrm{He}$ ratio as high as that of the upper mantle component. These results are regarded as an evidence of their slab-derived fluid origin (Nagao et al. 1981; Sano and Wakita 1985; Matsumoto et al. 2003; Morikawa et al. 2005; Kusuda et al. 2014). On the contrary, the ${ }^{3} \mathrm{He} /{ }^{4} \mathrm{He}$ ratio in sample KNK-16-M005, the one expected to best preserve the $\mathrm{He}$ and $\mathrm{Ne}$ composition of the KDE (Fig. 7), is 1.4 Ra (Table 1). Notably, this value indicates a significant mantle-derived component, but it is much lower than that obtained from the Arima brine samples. Our hypothesis to explain this difference is that the KDE originally had a ${ }^{3} \mathrm{He} /{ }^{4} \mathrm{He}$ ratio as high as that of the upper mantle component, but that it was reduced by the addition of radiogenic ${ }^{4} \mathrm{He}$ during its upwelling within the crust. If this hypothesis is correct, the KDE should have a longer residence time in the crust compared to the Arima end-member. This idea could be verified in the future by measuring long-lived radionuclides which is useful for estimating the residence time of saline water (e.g., ${ }^{36} \mathrm{Cl}$ ).

The fourth interesting feature is water temperature. Slab-derived fluids might have temperatures of a few hundreds of ${ }^{\circ} \mathrm{C}$ when generated, which are considered appropriate for dehydration reactions (Kazahaya et al. 2014). Incidentally, the water temperature of the Arima brine reaches $\sim 100{ }^{\circ} \mathrm{C}$ at surface (Masuda et al. 1985). Meanwhile, the estimated temperature of the KDE $\left(12{ }^{\circ} \mathrm{C}\right)$ is close to that of the river and of the small springs around the Kashio mineral spring. The KDE might have been substantially cooled during and/or after ascending to the surface. Two scenarios can be considered: one in which the ascending speed was slow enough to allow a thermal equilibrium between the water and the crustal rocks, and another in which the KDE water remained in the shallow crust for a long period of time after ascending, although it is difficult to quantitatively discuss the depth of the KDE's aquifer based solely on the available data. In any case, the KDE might have resided in the crust for a long time, in accordance with its relatively low ${ }^{3} \mathrm{He} /{ }^{4} \mathrm{He}$ ratio. The above issue needs to be further discussed in future works, together with the possibility that the upwelling movement of slab-derived fluid occurs in correspondence of the MTL, as in the Kinki district (Tanaka et al., 2013; Kazahaya et al. 2014; Morikawa et al. 2016).

\section{Conclusions}

(1) The concentration of $\mathrm{Cl}$ in the KDE (the deep brine end-member of the Kashio mineral spring), was carefully estimated based on the variations of ${ }^{3} \mathrm{H}$ and atmospheric ${ }^{20} \mathrm{Ne}$. The estimated value was not inconsistent with 
previous results, such as those of Masuda et al. (1988). Based on the estimated concentration of $\mathrm{Cl}$, we also obtained the chemical and isotopic compositions of the KDE.

(2) Based on these compositions and those reported in previous studies, we interpreted the origin of the KDE as a slab-derived fluid that may have undergone isotopic exchanges with minerals. Although the helium isotope ratio in the Kashio brine was significantly lower than in the Arima brine, $\sim 20 \%$ of the dissolved helium contained in the Kashio end-member was derived from the upper mantle (whereas the rest from the crust). This result supports the possibility of a slab-derived fluid origin.

(3) Although in previous studies the Kashio brine has been considered to have the same end-member as the Arima hot spring, it is not recommendable to interpret the $\mathrm{KDE}$ as a diluted Arima end-member, because the Kashio A brine and the KDE contain little amount of meteoric water (considering the content of atmospheric noble gas). The differences in chemical and isotopic compositions between the KDE and the Arima end-member may indicate a certain variety in the composition of the slab-derived fluid. The lower $\delta \mathrm{D}$ of the $\mathrm{KDE}$ seem to reflect its greater depth of dehydration compared to the Arima end-member. The reasons behind the observed carbon depletion and the possible long residence times of the KDE will be the subject of future studies.

\section{Abbreviations}

KDE: Kashio deep brine end-member; MTL: Median Tectonic Line; DIC: Dissolved inorganic carbon.

\section{Acknowledgements}

The authors would like to sincerely thank the owners of the wells for allowing the collection of the water samples. The authors also thank K. Kawamoto (Ooshika Geological Museum of Japan Median Tectonic Line) for guiding them around the mineral springs and outcrops of the study area. F. Tsunomori (Geochemical Research Center, Graduate School of Science, The University of Tokyo) is gratefully acknowledged for his constructive comments on this study. H. A. Takahashi, A. Inamura, and H. Handa are thanked for the analyses of water chemistry and of the hydrogen and oxygen isotope ratios.

\section{Authors' contributions}

FK conducted the sampling and noble-gas analyses and drafted the initial manuscript. KK coordinated the present work and helped FK to complete the manuscript. NM supported the noble-gas analyses. MY supported the sampling and in situ measurements. HT helped to complete the manuscript. MT conducted the ion chromatography and stable isotope analyses. YT measured the tritium concentration. All authors read and approved the final manuscript.

\section{Funding}

This study was partly supported by MEXT KAKENHI Grant Number JP26109006

\section{Availability of data and materials}

The dataset supporting the conclusions of this article is included within it.

Ethics approval and consent to participate

Not applicable.
Consent for publication

Not applicable.

\section{Competing interests}

The authors declare that they have no competing interests.

\section{Author details}

${ }^{1}$ Central Research Institute of Electric Power Industry (CRIEPI), 1646 Abiko, Abiko, Chiba 270-1 194, Japan. ${ }^{2}$ Institute of Earthquake and Volcano Geology, National Institute of Advanced Industrial Science and Technology (AIST), 1-1-1 Higashi, Tsukuba, Ibaraki 305-8567, Japan. ${ }^{3}$ Faculty of Geo-Environmental Science, Rissho University, 1700 Magechi, Kumagaya, Saitama 306-0194, Japan.

${ }^{4}$ Department of Earth and Planetary Science, Graduate School of Science, The University of Tokyo, 7-3-1 Hongo, Bunkyo-ku, Tokyo 113-0033, Japan.

Received: 9 September 2019 Accepted: 30 June 2020

Published online: 23 July 2020

\section{References}

Amita K, Ohsawa S, Du J, Yamada M (2005) Origin of Arima-type deep thermal water from hot spring wells in Oita Plain, eastern Kyushu, Japan. J Hot Spring Sci 55:64-77 (in Japanese with English abstract)

Amita K, Ohsawa S, Nishimura K, Yamada M, Mishima T, Kazahaya K, Morikawa N, Hirajima T (2014) Origin of saline waters distributed along the Median Tectonic Line in south-west Japan: hydrogeochemical investigation on possibility of derivation of metamorphic dehydrated fluid from subducting oceanic. J Japanese Assoc Hydrol Sci 44:17-38 (in Japanese with English abstract)

Asai K, Koshimizu S (2019) ${ }^{3} \mathrm{H} /{ }^{3} \mathrm{He}$-based groundwater ages for springs located at the foot of Mt. Fuji. J Groundw Hydrol 61:291-298 (in Japanese with English abstract)

Clark I, Fritz P (2000) Environmental isotopes in hydrogeology, 2nd edn. CRC Press LLC, Florida

Clayton RN, O'Neil JR, Mayeda TK (1972) Oxygen isotope exchange between quartz and water. J Geophys Res 77:3057-3067. https://doi.org/10.1029/ JB077i017p03057

Craig H (1961) Isotopic variations in meteoric waters. Science 133:1702-1703

Craig H (1963) The Isotopic geochemistry of water and carbon in geothermal areas, nuclear geology on geothermal areas. Spoleto 1963:17-53

Faure G (1977) Principles of isotope geology. Wiley, New York

Fukuyama M, Kawamoto T, Ogasawara M (2017) Chemical composition of fluid inclusions in the Yorii jadeite-quartz rocks from the Kanto Mountains, Japan. J Miner Petrol Sci 112:281-290. https://doi.org/10.2465/ jmps.170331

Giggenbach WF (1992) Isotopic shifts in waters from geothermal and volcanic systems along convergent plate boundaries and their origin. Earth Planet Sci Lett 113:495-510. https://doi.org/10.1016/0012-821X(92)90127-H

Hacker BR (2008) $\mathrm{H}_{2} \mathrm{O}$ subduction beyond arcs. Geochem Geophys Geosyst. https://doi.org/10.1029/2007GC001707

Hashizume T (1984) Geochemical study on occurence of $\mathrm{NaCl}$ type spring on the outer part (Ina Valley) of the Central Tectonic Line. J Hot Spring Sci 35:1-10 (in Japanese with English abstract)

Hirose F, Nakajima J, Hasegawa A (2008) Three-dimensional seismic velocity structure and configuration of the Philippine Sea slab in southwestern Japan estimated by double-difference tomography. J Geophys Res Solid Earth 113:1-26. https://doi.org/10.1029/2007JB005274

lizumi S (1968) The Ogawara ultrabasic intrusion, Nagano Prefecture in Central Japan (Part 1). Earth Sci J Assoc Geol Collab Japan 99:267-273

Isozaki Y, Maruyama S (1991) Studies on Orogeny based on Plate Tectonics in Japan and new geotectonic subvision of the Japanese Islands. J Geogr 100:697-761 (in Japanese with English abstract)

Ito T (2016) Crustal structure of the Izu collision zone revealed by recent seismic studies. In: The 123rd annual meeting of the Geological Society of Japan. (in Japanese)

Japan Meteorological Agency (2019) Japan Meteorological Agency Home Page. In: Japan Meteorol. Agency. https://www.data.jma.go.jp/obd/stats/ etrn/index.php. Accessed 10 Dec 2019

Jean-Baptiste P, Mantisi F, Dapoigny A, Stievenard M (1992) Design and performance of a mass spectrometric facility for measuring helium 
isotopes in natural waters and for low-level tritium determination by the ${ }^{3} \mathrm{He}$ ingrowth method. Int J Radiat Appl Instrumentation Part. https://doi. org/10.1016/0883-2889(92)90150-D

John T, Scambelluri M, Frische M, Barnes JD, Bach W (2011) Dehydration of subducting serpentinite: implications for halogen mobility in subduction zones and the deep halogen cycle. Earth Planet Sci Lett 308:65-76. https ://doi.org/10.1016/j.epsl.2011.05.038

Kaasalainen H, Stefánsson A (2012) The chemistry of trace elements in surface geothermal waters and steam. Chem Geol, Iceland. https://doi. org/10.1016/j.chemgeo.2012.08.019

Kato S, Kajiwara Y (1986) Isotopic composition of hydrogen and oxygen in waters associated with oil and gas from Niigata Basin, Japan. J Japanese Assoc Pet Technol 51:113-122 (in Japanese with English abstract)

Kato S, Yasuda Y, Nishida H (2000) Geochemistry of formation waters from oil and gas fields in Akita and Yamagata Prefectures, northeastern Japan. J Japanese Assoc Pet Technol 65:229-237 (in Japanese with English abstract)

Kawabata K (1984) Cretaceous Radiolarian Fossils occurred from the Shimanto Belt in the Toyama-gawa Area, Akaishi Mts., Central Japan, and its Geological Significance. Earth Sci J Assoc Geol Collab Japan 38:215-219 (in Japanese)

Kawabe I (1978) Calculation of oxygen isotope fractionation in quartz-water system with special reference to the low temperature fractionation. Geochim Cosmochim Acta 42:613-621. https://doi.org/10.1016/00167037(78)90006-6

Kawamoto T, Yoshikawa M, Kumagai Y, Mirabueno MHT, Okuno M, Kobayashi T (2013) Mantle wedge infiltrated with saline fluids from dehydration and decarbonation of subducting slab. Proc Natl Acad Sci 110:9663-9668. https://doi.org/10.1073/pnas.1302040110

Kazahaya K, Takahashi M, Yasuhara M, Nishio Y, Inamura A, Morikawa N, Sato T, Takahashi HA, Kitaoka K, Ohsawa S, Oyama Y, Ohwada M, Tsukamoto H, Horiguchi K, Tosaki Y, Kirita T (2014) Spatial distribution and feature of slab-related deep-seated fluid in SW Japan. J Japanese Assoc Hydrol Sci 44:3-16. https://doi.org/10.4145/jahs.44.3 (in Japanese with English abstract)

Kendrick MA, Scambelluri M, Honda M, Phillips D (2011) High abundances of noble gas and chlorine delivered to the mantle by serpentinite subduction. Nat Geosci 4:807-812. https://doi.org/10.1038/ngeo 1270

Kusuda C, Iwamori H, Nakamura H, Kazahaya K, Morikawa N (2014) Arima hot spring waters as a deep-seated brine from subducting slab. Earth Planets Space 66:119. https://doi.org/10.1186/1880-5981-66-119

$\mathrm{LiY-H} \mathrm{(1982)} \mathrm{A} \mathrm{brief} \mathrm{discussion} \mathrm{on} \mathrm{the} \mathrm{mean} \mathrm{oceanic} \mathrm{residence} \mathrm{time} \mathrm{of}$ elements. Geochim Cosmochim Acta 46:2671-2675. https://doi. org/10.1016/0016-7037(82)90386-6

Makimoto H (1978) Petrology of the Irisawai ultramafic complex in the Oshika district, Nagano Prefecture, central Japan. J Geol Soc Japan 84:317-329 (in Japanese with English abstract)

Masuda H, Sakai H, Chiba H (1985) Geochemical in Arima and characteristics its vicinity of $\mathrm{Na}-\mathrm{Ca}-\mathrm{Cl}-\mathrm{HCO}_{3}$ in the western Kinki type district waters Japan. Geochem J 19:149-162

Masuda H, Hashizume T, Sakai H (1988) Seasonal variation in chemical and isotopic compositions of Kashio brines and its interpretation. Geochemistry 22:149-156 (in Japanese with English abstract)

Matsubaya O (1981) Origin of hot spring waters based on hydrogen and oxygen isotopic ratios. J Hot Spring Sci 31:47-56 (in Japanese)

Matsubaya O (2009) What is definition of the Arima-type hot spring? J Hot Spring Sci 59:24-35 (in Japanese with English abstract)

Matsubaya O, Sakai H, Kusachi I, Satake H (1973) Hydrogen and oxygen isotopic ratios and major element chemistry of Japanese thermal water systems. Geochem J 7:123-151

Matsubaya O, Sakai H, Kusakabe M, Sasaki A (1980) An isotope study of hot springs in Nagano Prefecture. Papers of the Institute for Thermal Spring Research, Okayama University 50:17-24. (in Japanese with English abstract)

Matsuhisa Y, Goldsmith JR, Clayton RN (1978) Mechanisms of hydrothermal crystallization of quartz at $250^{\circ} \mathrm{C}$ and $15 \mathrm{kbar}$. Geochim Cosmochim Acta 42:173-182. https://doi.org/10.1016/0016-7037(78)90130-8

Matsuhisa Y, Goldsmith JR, Clayton RN (1979) Oxygen isotopic fractionation in the system quartz-albite-anorthite-water. Geochim Cosmochim Acta 43:1131-1140. https://doi.org/10.1016/0016-7037(79)90099-1
Matsumoto T, Kawabata T, Matsuda JI, Yamamoto K, Mimura K (2003) ${ }^{3} \mathrm{He} /{ }^{4} \mathrm{He}$ ratios in well gases in the Kinki district, SW Japan: surface appearance of slab-derived fluids in a non-volcanic area in Kii Peninsula. Earth Planet Sci Lett 216:221-230. https://doi.org/10.1016/S0012-821X(03)00479-5

Morgenstern U, Taylor CB (2009) Ultra low-level tritium measurement using electrolytic enrichment and LSC. Isot Environ Health Stud 45:96-117. https://doi.org/10.1080/10256010902931194

Morikawa N, Kazahaya K, Yasuhara M, Inamura A, Nagao K, Sumino H, Ohwada M (2005) Estimation of groundwater residence time in a geologically active region by coupling $4 \mathrm{He}$ concentration with helium isotopic ratios. Geophys Res Lett 32:1-4. https://doi.org/10.1029/2004GL021501

Morikawa N, Kazahaya K, Masuda H, Ohwada M, Nakama A, Nagao K, Sumino H (2008) Relationship between geological structure and helium isotopes in deep groundwater from the Osaka Basin: application to deep groundwater hydrology. Geochem J 42:61-74. https://doi.org/10.2343/geoch emj.42.61

Morikawa N, Kazahaya K, Takahashi M, Inamura A, Takahashi HA, Yasuhara M, Ohwada M, Sato T, Nakama A, Handa H, Sumino H, Nagao K (2016) Widespread distribution of ascending fluids transporting mantle helium in the fore-arc region and their upwelling processes: noble gas and major element composition of deep groundwater in the Kii Peninsula, southwest Japan. Geochim Cosmochim Acta 182:173-196. https://doi.org/10.1016/j. gca.2016.03.017

Muramatsu Y, Hamai T, Yamano T, Chiba H, Waseda A (2012) Hydrochemistry, Its Geological and Mineralogical Interpretations of Non-Volcanic Hot Springs in Boso Peninsula and Southeastern Ibaraki Prefecture, Central Japan. J Hot Spring Sci 62:112-134 (in Japanese with English abstract)

Muramatsu Y, Yagushi M, Chiba H, Okumura F, Ohba T (2016) Genesis of highly Saline hot spring waters from the southern Itoigawa-Shizuoka tectonic line and areas east-genetic analogy of the Kashio highly saline hot spring waters from the Median Tectonic Line - J J Hot Spring Sci 66:70-88 (in Japanese with English abstract)

Nagao K, Takaoka N, Matsubayashi O (1981) Rare gas isotopic compositions in natural gases of Japan. Earth Planet Sci Lett 53:175-188. https://doi. org/10.1016/0012-821X(81)90152-7

Nakajima J, Hasegawa A (2007) Subduction of the Philippine Sea plate beneath southwestern Japan: slab geometry and its relationship to arc magmatism. J Geophys Res Solid Earth 112:1-18. https://doi. org/10.1029/2006JB004770

Nakamura H, Maeda K (1958) Thermal saline waters in Japan. Bull Geol Surv Japan 9:431-440 (in Japanese with English abstract)

Nishimura S, Katsura I, Nishida J (2006) Geological structure of Arima Hotspring. J Hot Spring Sci 56:3-15 (in Japanese with English abstract)

Nugraha AD, Mori J (2006) Three-dimensional velocity structure in the Bungo Channel and Shikoku area, Japan, and its relationship to low-frequency earthquakes. Geophys Res Lett 33:1-5. https://doi.org/10.1029/2006G L028479

Obara K (2002) Nonvolcanic deep tremor associated with subduction in southwest Japan. Science 296:1679-1681. https://doi.org/10.1126/scien ce. 1070378

Ozima M, Podosek FA (2002) Noble gas geochemistry. Cambridge University Press, Cambridge

Sakai H, Matsuhisa Y (1996) Stable isotope geochemistry, 1st edn. University of Tokyo Press, Tokyo (in Japanese)

Sakai T, Ohsawa S, Yamada M, Mishima T, Oue K (2013) A formation mechanism and the origin of Yamaga hot spring in Oita Prefecture inferred from geochemical data of hot spring waters and their accompanied gases. J Hot Spring Sci 63:164-183 (in Japanese with English abstract)

Sano Y, Fischer TP (2013) The Analysis and Interpretation of Noble Gases in Modern Hydrothermal Systems. In: Burnard P (ed) The Noble gases as geochemical tracers. Springer, Berlin, pp 249-317

Sano Y, Wakita H (1985) Geographical distribution of ${ }^{3} \mathrm{He} /{ }^{4} \mathrm{He}$ ratios in Japan: implications for arc Tectonics and incipient magmatism. J Geophys Res 90:8729-8741

Shibata K, Takagi H (1988) Isotopic ages of rocks and intrafault materials along the Median Tectonic Line-an example in the Bungui-toge area, Nagano Prefecture. J Geol Soc Japan 94:35-50 (in Japanese with English abstract)

Suzuoki T, Epstein S (1976) Hydrogen isotope fractionation between OHbearing minerals and water. Geochim Cosmochim Acta 40:1229-1240. https://doi.org/10.1016/0016-7037(76)90158-7 
Takagi H, Shibata K, Uchiumi S (1991) K-Ar ages of fault gouges and felsite dykes from the Median Tectonic Line in Shubu Region, central Japan. J Geol Soc Japan 97:377-384. https://doi.org/10.1061/ASCE-1090-02412003-29 (in Japanese with English abstract)

Takamatsu N, Imahashi M, Kamimura K, Tsutsumi M (1986) Geochemical implication of the lithium content of saline spring waters in Japan. Geochem J 20:143-151. https://doi.org/10.2343/geochemj.20.143

Tanaka H, Hara T (1990) Dextral movement of the Median Tectonic Line before early Miocene as revealed from textures of brittle fault rocks. J Geol Soc 96:331-334. https://doi.org/10.1248/cpb.37.3229 (in Japanese)

Tanaka K, Seki R, Ikeda N (1984) Geochemical study of Arima hot-spring waters, Hyogo, Japan, by means of tritium and deuterium. Geochem J 18:173-180

Tanaka H, Takagi H, Inoue M (1996) Mode of cataclastic deformation and hydrothermal alteration of the fault rocks and history of fault activity along the Median Tectonic Line, central Japan. Kozo-Chishitu 41:31-44 (in Japanese)

Tanaka A, Yano Y, Sasada M, Okubo Y, Umeda K, Nakatsuka N, Akita F (1999) Compilation of thermal gradient data in Japan on the basis of the temperatures in boreholes. Bull Geol Surv Japan 50:457-487 (in Japanese with English abstract)
Tanaka K, Higashida Y, Murakami H (2013) Deep-seated fluid around the Median Tectonic Line, Kii Peninsula and its relationship to geologic structure. J Japanese Assoc Hydrol Sci 43:137-150 (in Japanese with English abstract)

Uesugi J, Arai S (1999) The Shiokawa peridotite mass in the Mikabu belt, central Japan, as a cumulate from intra-plate tholeiite. Mem Geol Soc Japan 52:229-242 (in Japanese with English abstract)

Yamada E, Abe K, Yamada T, Goto S, Ito Y (1973) On Koshibu hot springs in Oshika-Mura, Nagano Prefecture. In: 26th Annual Meeting of the Balneological Society of Japan. Japan

\section{Publisher's Note}

Springer Nature remains neutral with regard to jurisdictional claims in published maps and institutional affiliations.

\section{Submit your manuscript to a SpringerOpen ${ }^{\odot}$ journal and benefit from:}

- Convenient online submission

$\checkmark$ Rigorous peer review

- Open access: articles freely available online

- High visibility within the field

- Retaining the copyright to your article

Submit your next manuscript at $\gg$ springeropen.com 